
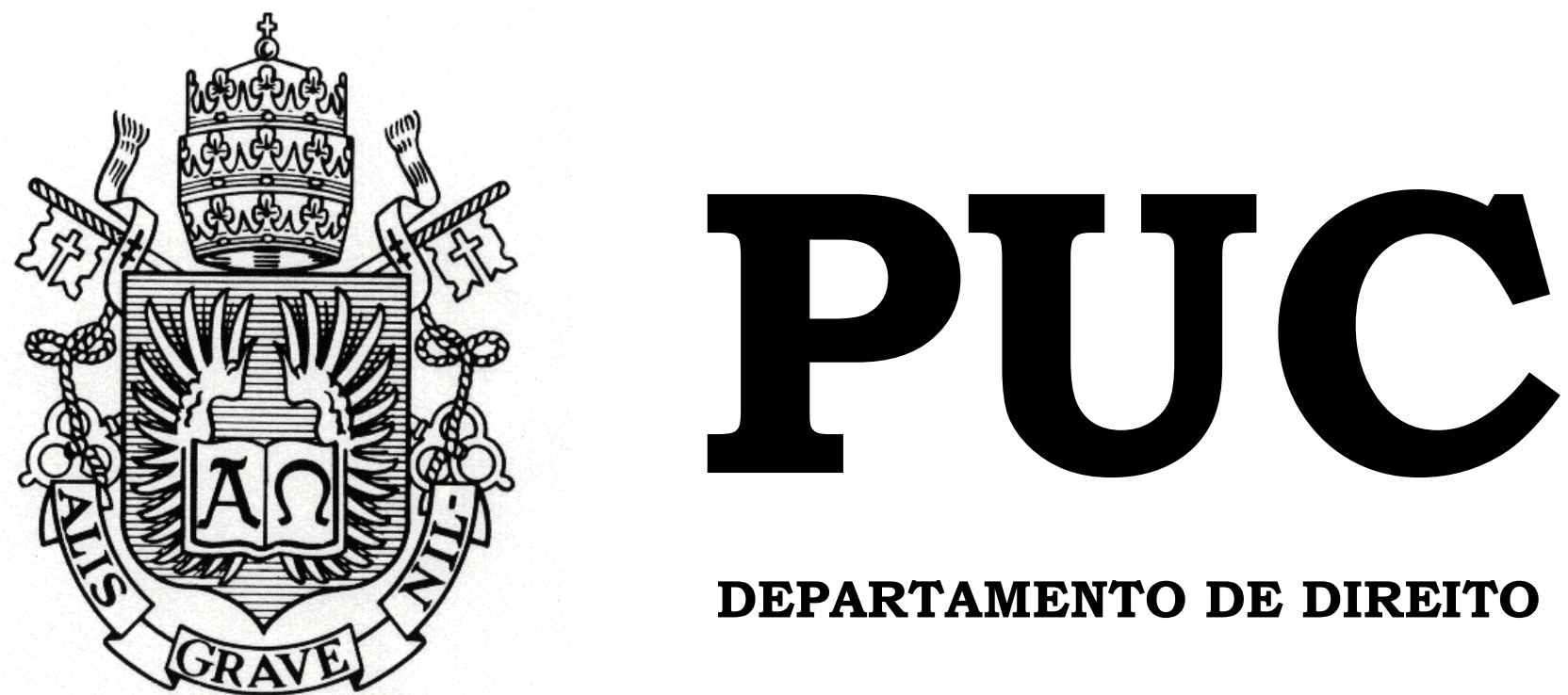

DEPARTAMENTO DE DIREITO

Plain PACKAGING: RESTRIÇÕES DE MARCA EM EMBALAGENS PARA EMPRESAS DE CIGARRO E SUAS CONSEQUÊNCIAS NA PROPRIEDADE INTELECTUAL

por

Camila Neves Rodrigues da Silva

ORIENTADORA: Prof. Nádia de Araújo

2014.1

PONTIFÍCIA UNIVERSIDADE CATÓLICA DO RIO DE JANEIRO

RUA MARQUÊS DE SÃO VICENTE, 225 - CEP 22453-900

RIO DE JANEIRO - BRASIL 


\title{
PLAIN PACKAGING: RESTRIÇÕES DE MARCA EM EMBALAGENS PARA EMPRESAS DE CIGARRO E SUAS CONSEQUÊNCIAS NA PROPRIEDADE INTELECTUAL
}

\author{
por \\ Camila Neves Rodrigues da Silva
}

Monografia apresentada ao Departamento de Direito da Pontificia Universidade Católica do Rio de Janeiro (PUC-Rio) para a obtenção do Título de Bacharel em Direito.

Orientadora: Nádia de Araújo 
Aos meus pais, avós, Gabi e Pedro. 


\section{Resumo e Palavras-Chave}

$\mathrm{O}$ presente estudo pretende analisar a possibilidade $\mathrm{e}$ as consequências da aplicação do chamado Plain Packaging no Brasil.

Para tanto, inicialmente, há uma breve exposição do histórico do instituto, seguida de sua repercussão em diversos países e um exemplo onde já existe, a Austrália. Não será abordada a repercussão e andamento do Plain Packaging em demais países, somente em linhas gerais para contextualizar a medida.

Em seguida, há uma abordagem crítica das principais teses que fundamentam os dois pólos do debate, dentro e fora do Brasil.

Adiante, procura-se demonstrar a situação do Plain Packaging no Brasil, as áreas do Direito relacionadas e o cenário atual em torno da medida.

Por fim, cuida-se das potenciais violações ao Direito de Propriedade Intelectual, afetado por uma possível implementação do Plain Packaging no Brasil.

Direito da Propriedade Intelectual - Marcas - Desapropriação Indenização - Caducidade - Cigarro 


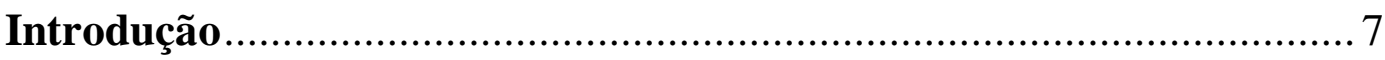

\section{$\underline{\text { Parte I }}$}

Capítulo I - Introdução ao conceito do Plain Packaging ....................... 10

I.1. Conceituação e delineamento .................................................... 10

I.2. Situação da regulamentação de produtos fumígenos no mundo ....... 13

Capítulo II - Um exemplo: A decisão pioneira do Governo Australiano

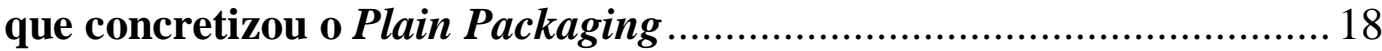

II.1. A decisão Australiana............................................................. 18

II.2. Breve análise de Direito Comparado ............................................. 20

II.3. Argumentos dos dois pólos de interesse ....................................... 23

\section{$\underline{\text { Parte II }}$}

Capítulo III - Plain Packaging no Brasil ............................................... 29

III.1. Contexto das restrições de cigarro no Brasil ...................................2 29

III.2. Plain Packaging no Brasil............................................................. 31

III.3. Relação com o Direito Constitucional ............................................... 32

III.4. Relação com o Direito da Concorrência ........................................... 33

III.5. Relação com o Direito Administrativo …………………………........ 36

III.6. Relação com o Direito do Consumidor .............................................. 38

III.7. Relação com o Direito da Propriedade Intelectual ............................ 39 
Capítulo IV - As consequiências da restrição na Propriedade

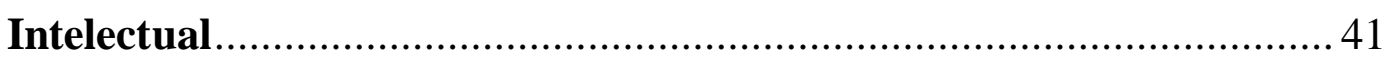

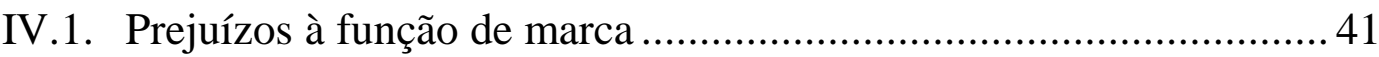

IV.2. Plain Packaging: Expropriação marcaria?....................................... 43

IV.3. Caducidade da marca expropriada ................................................... 45

IV.4. Marca: direito positivo e negativo ou só negativo? ........................... 47

IV.5. Posição das entidades de Propriedade Industrial sobre o tema ....... 48

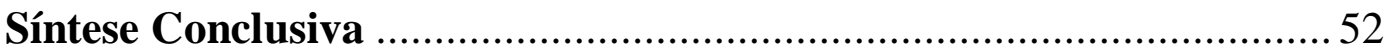

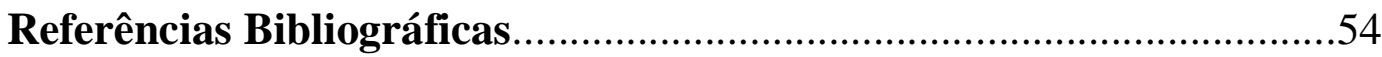




$\begin{array}{ll}\text { art. } & - \text { Artigo } \\ \text { CF } & - \text { Constituição Federal } \\ \text { CF/88 } & - \text { Constituição Federal de } 1988 \\ \mathrm{n}^{\circ} & - \text { número } \\ \mathrm{p} . & - \text { página } \\ \text { v. } & - \text { Volume } \\ \text { vol. } & - \text { Volume } \\ \S & - \text { Parágrafo } \\ \text { PVD } & - \text { Ponto de Venda } \\ \text { TRIPS } & - \text { Trade Related Aspects of Intellectual Property Rights } \\ \text { CUP } & - \text { Convenção da União de Paris } \\ \text { LPI } & - \text { Lei da Propriedade Industrial } \\ \text { BAT } & - \text { British American Tobacco } \\ \text { PLS } & - \text { Projeto de Lei do Senado }\end{array}$




\section{Introdução}

A medida do Plain Packaging relacionada a cigarros vem sendo alvo de discussões no mundo todo, principalmente depois do governo australiano ter sido, de forma pioneira, o primeiro e único país a colocá-la em prática. Com tal instituto, a embalagem resta padronizada, sem qualquer elemento marcário que não seja meramente nominativo, aparecendo em letra de fonte, cor e tamanho padrão.

Já são incontáveis os pareceres e documentos escritos sobre o tema, dada a importância da medida sobre diversas áreas do direito e da economia, tendo em vista tratar-se de medida restritiva.

Uma área fortemente atingida é a da Propriedade Intelectual, especificamente no que tange às marcas, que são quase que totalmente retiradas da embalagem de produtos fumígenos. Este é o enfoque desta monografia, ou seja, buscar-se-á estudar os efeitos do Plain Packaging no Brasil dentro da área de propriedade intelectual, limitando-se assim o estudo.

Para abordar este tão instigante e controverso assunto, o presente estudo é dividido em quatro Capítulos, além da presente Introdução.

Esta monografia, portanto, buscará dar um panorama geral sobre a padronização dos cigarros, para, ao fim, tratar especificamente das consequências de tal restrição nos direitos de propriedade intelectual no Brasil. O conceito e delineamento sobre o assunto será feito logo no primeiro capítulo, para melhor entendimento do restante do estudo, bem como uma exposição da situação da regulamentação dos produtos de tabaco no mundo.

Não obstante, em seguida, tratar-se-á sobre os tratados em vigor que tem como tema a propriedade intelectual e suas limitações e/ou permissões a medidas restritivas. Destaca-se que o Brasil faz parte destes tratados e, portanto, deve seguir suas orientações. 
A seguir, o Capítulo II tratará, a termo de exemplo, sobre a concretização do Plain Packaging na Australia, abordando a legislação, as controvérsias, as ações propostas pela indústria fumageira e a decisão final da justiça australiana que tornou real de uma vez por todas as embalagens genéricas.

Buscará trazer também os principais argumentos utilizados pelos dois pólos de interesse (quais sejam, o governo e órgãos relacionados à saúde versus a indústria tabageira e órgãos de defesa da propriedade intelectual) para defender ou criticar a medida.

Adiante, na segunda Parte deste estudo, far-se-á uma análise do histórico regulatório sobre a indústria de cigarro no Brasil, demonstrando a crescente intervenção do Estado neste ramo comercial.

No mesmo capítulo, será tratado como o fenômeno se daria no Brasil, explorando as áreas do direito diretamente afetadas pela medida do Plain Packaging, e quais as suas consequências no Direito Brasileiro.

Para tanto, serão identificadas, uma a uma, as ligações e consequências das áreas de Direito Constitucional, Direito da Concorrência, Direito Administrativo e Direito do Consumidor chegando, ao fim, a uma breve análise do que será abordado em capítulo destinado à propriedade intelectual.

No mesmo sentido, será exposto como o Plain Packaging vem sendo explorado no Brasil. A discussão é crescente e tramita, inclusive, um projeto de lei do Senado que pretende a sua implementação no Brasil.

Ao fim, chega-se ao capítulo final, foco deste estudo, que, por sua vez, se dedicará a investigação das consequências da embalagem padronizada para os titulares de marcas de cigarro.

Para tal, o instituto será analisado à luz da Constituição Brasileira, bem como da lei da Propriedade Intelectual.

Serão, ao longo do referido Capítulo, expostos os prejuízos à função de marca, bem como as discussões que devem ser delineadas a fim de se definir se a medida constitui expropriação marcaria e se deve ser 
acompanhada de indenização aos titulares de registros e pedidos de registro de marcas de cigarro, bem como se, estando presente, de que forma deve ser feita tal indenização, se considerada constitucional a medida.

Ademais, será abordado o fato de que as marcas, se implementado o Plain Packaging, serão postas ao não uso, o que, possivelmente, trará a discussão da perda da marca pela caducidade, prevista na lei da propriedade intelectual.

Por óbvio, não se terá a ambiciosa pretensão de se esgotar o estudo sobre o tema, já que, como não existe ainda no Brasil (e mesmo na Austrália é uma medida recentíssima), é impossível prever precisamente quais serão as consequências da medida na prática.

É inviável, portanto, antecipar com precisão suas infinitas possibilidades e consequências, bem como suas particularidades no Brasil, que serão determinadas pelo caso concreto.

Conclui-se o presente estudo, portanto, com uma breve análise de todo o tema abordado, onde serão resumidas as principais ideias expostas ao longo da monografia. 


\section{PARTE I}

\section{CAPÍTULO I - Introdução ao conceito do Plain Packaging}

No presente Capítulo buscar-se-á conceituar o tema central desta monografia, qual seja, o Plain Packaging, e traçar um panorama geral da regulamentação dos produtos relacionados ao tabaco no mundo, de forma a estudar como os tratados internacionais (em que, inclusive, o Brasil é parte) tratam do tema de forma direta e indireta.

\section{I.1. Conceituação e delineamento}

O termo Plain Packaging, ainda sem tradução exata para o português, mas geralmente traduzido como "embalagem genérica", "embalagem padronizada" e "embalagem plana" engloba o conceito de embalagem genérica ou padronizada. Em outras palavras, significa retirar todo e qualquer elemento marcário da embalagem de um produto que não seja meramente nominativo. Assim, não resta elemento figurativo ou misto, mas apenas a parte nominativa da marca em letra, cor e tamanho padrão.

Cabe ressaltar, ainda, que a padronização estende-se aos cigarros em si, que também são igualados, na mesma forma das embalagens (cor e tamanho).

Trata-se de medida restritiva dirigida a produtos nocivos. No presente trabalho, especificamente e unicamente, tratar-se-á da sua aplicação em produtos fumígenos, tendo em vista que é o único ramo onde efetivamente tal medida já foi implementada, como se verá adiante.

O Plain Packaging já está em vigor na Austrália ${ }^{1}$, país que, de forma pioneira, deu início a tal medida no final de 2011, e vem sendo discutido por outros países, alguns em forma de consulta pública, como, por exemplo,

\footnotetext{
${ }^{1}$ AUSTRALIAN GOVERNMENT. Tobacco Plain Packaging Act 2011. Disponível em <http://www.comlaw.gov.au/Details/C2011A00148/Download>. Acesso em 11/04/2014.
} 
Reino Unido ${ }^{2}$, Nova Zelândia ${ }^{3}$, França ${ }^{4}$, Bélgica ${ }^{5}$ e Turquia ${ }^{6}$. Neste estudo, somente será tratado o Plain Packaging na Australia, a termo de exemplo, e no Brasil.

A União Europeia também considerou o uso do Plain Packaging no contexto de uma consulta pública sobre uma possível revisão da Diretiva de Produtos de Tabaco 2001/37 sobre produção e venda de cigarros. ${ }^{7}$ No início de 2014, o Parlamento Europeu aprovou a nova Diretiva de Produtos de Tabaco.

A nova Diretiva autoriza especificamente os Estados-Membros a introduzir medidas relativas à uniformização de embalagens se se justificarem por razões de saúde pública e se forem proporcionais, além de não conduzirem a barreiras sub-reptícias ao comércio entre os Estados-Membros ${ }^{8}$.

\footnotetext{
${ }^{2}$ No contexto de uma consulta sobre o futuro do controle sobre o tabaco, ficou decidido que o Plain Packaging ainda tinha benefícios meramente especulativos. Vide DEPARTMENT OF HEALTH. Consultation on the future of tobacco control. Disponível em <http://webarchive.nationalarchives.gov.uk/20130107105354/http://www.dh.gov.uk/prod_consum _dh/groups/dh_digitalassets/documents/digitalasset/dh_085651.pdf >. Acesso em 04 de maio de 2014.

${ }^{3}$ Após o fim do prazo para envio de submissões, em Outubro de 2012, o Governo decidiu prosseguir com o Plain Packaging e um projeto de lei foi apresentado em dezembro de 2013. Vide MINISTRY OF HEALTH. Proposal to introduce plain packaging of tobacco products in New Zealand. Disponível em <http://www.smoke-free.ca/trade-and-tobacco/New\%20Zealand/proposalto-introduce-plain-packaging-tobacco-products-in-nz-consultation.pdf> e projeto de lei Smokefree Environments (Tobacco Plain Packaging) Amendment Bill. Disponível em <http://www.legislation.govt.nz/bill/government/2013/0186/latest/whole.html\#DLM5821008> Acesso de ambos em 04 de maio de 2014.

${ }^{4}$ Uma proposta do partido UMP foi feita em 2010, mas não prosperou e foi arquivada. Vide HEURTAUT, Diane. Tabac: la Ligue contre le cancer veut des paquets de cigarettes "neutres" . Disponível em <http://lci.tf1.fr/science/tabac-la-ligue-contre-le-cancer-veut-des-paquets-decigarettes-6968916.html> e THE CONNEXION. Plain cigarette packets considered. Disponível em <http://www.connexionfrance.com/plain-cigarette-packets-smoking-draft-law-logos-coloursbanned-shock-images-view-article.html > Acesso de ambos em 04 de maio de 2014.

${ }^{5}$ Em 2011 o Ministro da Saúde da Bélgica, em resposta a uma pergunta no Parlamento, manifestou apoio a embalagem genérica.

${ }^{6}$ Em setembro de 2011, o site da Bloomberg informou que o governo turco estava trabalhando em regulamentos embalagem simples. Vide HARVEY, Benjamin. Turkey Working on Cigarette Branding Ban Law, Milliyet Says. Disponível em <http://www.bloomberg.com/news/2011-0907/turkey-working-on-cigarette-branding-ban-law-milliyet-says.html> Acesso em 04 de maio de 2014

${ }^{7}$ BONADIO, Enrico. Plain Packaging of Tobacco Products under EU Intellectual Property Law. Disponível em

file:///C:/Documents\%20and\%20Settings/Gelson/Meus\%20documentos/Downloads/SSRNid2174453.pdf >. Acesso em 14 de maio de 2014.

${ }^{8}$ Segundo nota informativa da União Européia. EUROPA.EU. Perguntas e respostas: Novas regras para os produtos do tabaco. Disponível em <http://europa.eu/rapid/press-release_MEMO14-134_pt.htm>. Acesso em 01 de maio de 2014
} 
Em maio de 2013, a Irlanda anunciou que seria o segundo país do mundo a adotar o Plain Packaging, iniciando estudos para a sua concretização ${ }^{9}$.

Um fato importante a ser considerado é que a intervenção do Estado se faz em produto lícito que gera riquezas ao país, tal como qualquer outro, principalmente ao se considerar a alta carga tributária que envolve sua comercialização. Isto ocorre tanto no Brasil como na Austrália.

Tal medida possui impactos em diversas áreas do Direito, como, por exemplo, onde parece mais latente, no que concerne aos direitos de propriedade intelectual, especialmente no que diz respeito às marcas. Esta área será especialmente abordada neste estudo.

O investimento, o valor econômico e a propriedade das marcas de cigarro são postos em questão, já que não é permitido o uso de cores, logos e estilizações. Este assunto será tratado em capítulo específico.

Ademais, existem tratados, como se verá adiante, que limitam e autorizam medidas que concernem à propriedade intelectual e que delineiam as possibilidades de medidas como Plain Packaging.

Como se verá à frente, ainda não existe Plain Packaging no Brasil. No entanto, a discussão sobre uma possível introdução da medida já existe. Tramita projeto de lei do $\operatorname{senado}^{10}$ que têm como escopo alterar a Lei Federal 9.294/1996 ${ }^{11}$, que dispõe sobre as restrições ao uso e à propaganda de produtos fumígenos (entre outros) com base no artigo 220 da Constituição Federal para retirar elementos gráficos da embalagem, restando apenas a marca nominativa do produto, em cor e letra padrão.

\footnotetext{
${ }^{9}$ DEPARTMENT OF HEALTH. Ireland set to become second country in the world to introduce plain pack cigarettes. Disponível em <http://www.dohc.ie/press/releases/2013/20130528.html>. Acesso em 11/04/2014.

10 Vide PLS 103 de $2014 . \quad$ Disponível em $\langle$ http://www.senado.gov.br/atividade/Materia/detalhes.asp?p_cod_mate=116679>. Acesso em 27 de março de 2014.

${ }^{11}$ A Lei Federal 9.294 de 1996 trata sobre as restrições à propaganda e publicidade de cigarro.
} 


\section{I.2. Situação da regulamentação de produtos fumígenos no mundo}

Como adiantado em parágrafo acima, existem alguns tratados internacionais que tem como objetivo uniformizar entendimentos acerca da propriedade intelectual por parte de seus membros.

Assim, as restrições introduzidas pelo Plain Packaging nas embalagens de produtos (neste caso, de produtos de tabaco) estão limitadas e delineadas pelos acordos internacionais ratificados, inclusive, pelo governo brasileiro. É o caso do TRIPS ${ }^{12}$ (Trade Related Aspects of Intellectual Property Rights) e da CUP ${ }^{13}$ (Convenção da União de Paris).

A proibição do uso da marca em sua plenitude pode resultar em diversas violações de cunho internacional, tendo em vista que os países signatários (entre eles, o Brasil) ratificaram tratados de Propriedade Intelectual que tratam sobre o assunto.

A imposição de restrições sobre o registro e uso de marcas registradas com base na natureza das mercadorias ou serviços em que são registradas pode ser entendida, por exemplo, como uma violação ao artigo 7 da CUP e do artigo 15 (4) do TRIPs, que dispõem que "A natureza dos bens ou serviços para os quais se aplique uma marca não constituirá, em nenhum caso, obstáculo a seu registro". ${ }^{14}$ A implementação do Plain Packaging pode criar um bloqueio indireto ao registro, pois impede o uso de uma marca registrada.

No mesmo sentido, o art. 8.1. do TRIPs estabelece que são permitidas medidas "necessárias para proteger a saúde e nutrição públicas e para promover o interesse público em setores de importância vital para seu desenvolvimento socioeconômico e tecnológico, desde que estas medidas

\footnotetext{
${ }^{12} \mathrm{O}$ TRIPS é um acordo internacional que busca reduzir as distorções e barreiras ao comércio internacional, bem como estabelecer padrões e princípios relativos à propriedade intelectual e ao comércio. Vide WORLD TRADE ORGANIZATION. TRIPS: AGREEMENT ON TRADERELATED ASPECTS OF INTELLECTUAL PROPERTY RIGHTS. Disponível em <http://www.wto.org/english/tratop_e/trips_e/t_agm1_e.htm>. Acesso em 04 de maio de 2014.

${ }^{13}$ De modo semelhante ao TRIPS, a CUP é um acordo internacional que tem o objetivo de proteção da propriedade intelectual. Vide INPI. Convenção de Paris. Disponível em 〈http://www.inpi.gov.br/images/stories/CUP.pdf〉. Acesso em 04 de maio de 2014.

${ }^{14}$ Ibid.
} 
sejam compatíveis com o disposto neste Acordo" ${ }^{\prime 15}$. Sem justificativa concreta, a medida torna-se um ônus injustificado, o que é proibido pelos tratados, como se verá à frente.

$\mathrm{O}$ artigo $6^{\circ}$ quinquies da CUP determina que qualquer marca regularmente registrada no país de origem será admitida para registro e protegida na sua forma original nos outros países da União, com restrição somente a quando forem suscetíveis de prejudicar direitos de terceiros em tal país, quando forem desprovidas de caráter distintivo ou composta somente de sinais de indicação, bem como quando for contrária à ordem pública e enganar o público ${ }^{16}$. Assim, como as marcas que sofreriam com o Plain Packaging não estão incluídas nestas exceções, pode-se considerar o Plain Packaging como uma violação, já que, mesmo que indiretamente, se obsta o registro de tais marcas. De nada adianta registrar a marca para uma classe de produtos de tabaco e não poder usá-la de forma íntegra.

Já o art. 10bis da CUP versa sobre a obrigação de assegurar a proteção efetiva contra a concorrência desleal, particularmente sobre atos suscetíveis de estabelecer confusão e induzir a erro sobre a natureza, modo de fabricação e características ${ }^{17}$.

Ao impedir a utilização de marcas registradas de titulares da indústria fumageira, a legislação de Plain Packaging pode vir a remover a medida mais eficaz de proteção que existe contra a concorrência desleal, e, especificamente, contra falsificação, podendo violar também o artigo acima.

O artigo 20 do TRIPs dispõe que não existirá qualquer ônus injustificado ao uso de uma marca registrada mediante a imposição de "exigências especiais" para esse uso, tal como o "uso em detrimento de sua capacidade de distinguir os bens e serviços de uma empresa daqueles de

\footnotetext{
15 ACORDO SOBRE ASPECTOS DOS DIREITOS DE PROPRIEDADE INTELECTUAL RELACIONADOS AO COMÉRCIO (ACORDO TRIPS OU ACORDO ADPIC) (1994). Disponível em <www2.cultura.gov.br/site/wp-content/uploads/2008/02/ac_trips.pdf>. Acesso em 04 de maio de 2014.

${ }^{16}$ Vide INPI. Convenção de Paris. Disponível em

<http://www.inpi.gov.br/images/stories/CUP.pdf>. Acesso em 04 de maio de 2014.

${ }^{17}$ Ibid.
} 
outra empresa ${ }^{18 \%}$. A questão, aqui, é determinar se seria um ônus justificado ou não.

A justificativa para projetos relacionados à melhora da saúde pública por meio do Plain Packaging é válida e nobre. O Plain Packaging Act da Austrália tem como objetivo melhorar a saúde pública, de modo a desencorajar as pessoas a começarem a fumar, incentivar as pessoas a deixar de fumar, evitar recaídas dos que já pararam de fumar e reduzir a exposição das pessoas à fumaça de produtos de tabaco ${ }^{19}$. Da mesma forma, o projeto que tramita no Brasil também busca melhorias na política de controle ao tabagismo ${ }^{20}$.

Porém, é possível que existam alternativas menos restritivas e que atinjam objetivos semelhantes, o que tornaria a restrição injustificada.

Por outro lado, o Brasil faz parte da Convenção-Quadro para o Controle do Tabaco (CQCT) ${ }^{21}$, que entrou em vigor em internacional em 27 de fevereiro de 2005, e para o Brasil em $1^{\circ}$ de fevereiro de 2006.

Tal tratado tem origem na Organização Mundial de Saúde e tem como objetivo "proteger as gerações presentes e futuras das devastadoras consequências sanitárias, sociais, ambientais e econômicas geradas pelo consumo e pela exposição à fumaça do tabaco, proporcionando uma referência para as medidas de controle do tabaco, a serem implementadas pelas Partes nos níveis nacional, regional e internacional, a fim de reduzir

\footnotetext{
${ }^{18}$ ACORDO SOBRE ASPECTOS DOS DIREITOS DE PROPRIEDADE INTELECTUAL RELACIONADOS AO COMÉRCIO (ACORDO TRIPS OU ACORDO ADPIC) (1994). Op. Cit.

${ }^{19}$ Vide item 3 do Plain Packaging Act de 2011. AUSTRALIAN GOVERNMENT. Tobacco Plain Packaging Act 2011. Op. Cit.

${ }^{20}$ Vide PLS 103 de 2014. Disponível em

$\langle$ http://www.senado.gov.br/atividade/Materia/detalhes.asp?p_cod_mate=116679>. Acesso em 27 de março de 2014.

${ }^{21}$ A Convenção-Quadro para o Controle do Tabaco (CQCT) é o primeiro tratado internacional de saúde pública da Organização Mundial da Saúde e representa um instrumento de resposta dos 192 países membros da Assembléia Mundial da Saúde à crescente epidemia do tabagismo em todo mundo. Vide INCA. OBSERVATÓRIO DA POLÍTICA NACIONAL DE CONTROLE DO TABACO.

<http://www2.inca.gov.br/wps/wcm/connect/observatorio_controle_tabaco/site/home/convencao_ quadro/o_que_e>. Acesso em 04 de maio de 2014.
} 
de maneira contínua e substancial a prevalência do consumo e a exposição à fumaça do tabaco",22.

O referido tratado busca "prevenir a iniciação, promover e apoiar a cessação e alcançar a redução do consumo de tabaco em qualquer de suas formas" (art. $4^{\circ}$ ), de modo que as parte deverão "adotar e implementar medidas legislativas, executivas, administrativas e/ou outras medidas e cooperar, quando apropriado, com outras Partes na elaboração de políticas adequadas para prevenir e reduzir o consumo de tabaco, a dependência da nicotina e a exposição à fumaça do tabaco." (art. $\left.5^{\circ}\right) .^{23}$

Da mesma forma, o artigo 11 da Convenção-Quadro para o Controle do Tabaco defende a adoção de embalagem e etiquetagem que não induzam o consumidor a erro com relação a efeitos à saúde, riscos e emissões de produtos de tabaco ${ }^{24}$. Esse artigo pode, então, englobar o Plain Packaging.

Já o artigo 13 do referido tratado determina que as partes se comprometem a "proibir toda forma de publicidade, promoção e patrocínio do tabaco". No entanto, claramente diz que tal proibição se dará "segundo sua Constituição ou seus princípios constitucionais" ${ }^{25}$.

Desta forma, há um conflito entre os tratados citados que, no entanto, podem ser ponderados pelo fato de possivelmente haver medidas menos gravosas que podem ser implementadas visando o mesmo objetivo, de forma que os tratados não sejam violados.

É preciso, ao considerar a prática de uma medida restritiva de direitos, ponderar seus benefícios e consequências negativas por meio de uma análise de proporcionalidade, que envolve um julgamento de adequação da medida para alcançar a finalidade para que se destina, bem como uma análise da necessidade de tal medida, averiguando se há outra

\footnotetext{
${ }^{22}$ DECRETO No 5.658, DE 2 DE JANEIRO DE 2006. Disponível em <http://www.planalto.gov.br/ccivil_03/_Ato2004-2006/2006/Decreto/D5658.htm>. Acesso em $09 / 04 / 2014$.

23 Ibid.

${ }^{24}$ ACTBR. EMBALAGEM GENÉRICA DE PRODUTOS DE TABACO: PROTEGENDO CRIANÇAS, ADOLESCENTES E JOVENS DO MARKETING DA INDÚSTRIA DO TABACO. Disponível em <www.actbr.org.br/uploads/conteudo/738_embalagem_generica.pdf.> Acesso em 08/04/2014.

${ }^{25}$ DECRETO N ${ }^{\circ}$ 5.658, DE 2 DE JANEIRO DE 2006. Op. Cit.
} 
medida tão eficaz quanto mas menos restritiva, e, por fim, a verificação da proporcionalidade em sentido estrito, de forma a confirmar se a medida trás maiores vantagens que desvantagens.

O descumprimento de tratados, seja no sentido de introduzir ou não o Plain Packaging, pode gerar um mal estar internacional por conta de descumprimentos a disposições previamente estabelecidas. Assim, para evitar tal cenário, é necessário estudar se existem e quais seriam as medidas substitutivas ao Plain Packaging, obedecendo à proporcionalidade para atingir objetivos de forma menos restritiva a direitos. 


\section{CAPÍTULO II - Um exemplo: A decisão pioneira do governo Australiano que concretizou o Plain Packaging}

No presente Capítulo buscar-se-á analisar a decisão da Austrália sobre introduzir a medida relativa a embalagens genéricas e os argumentos que levaram à discussão e recursos por parte da indústria fumageira e o contrário, os argumentos de apoio por parte das ONGs e associações.

\section{II.1. A decisão Australiana}

A Austrália, de forma pioneira, implementou o Plain Packaging no país, inovando na busca pela proteção da saúde da população. A medida foi publicada em novembro de 2011, com início de aplicação em 2012.

O Tobacco Plain Packaging Act $2011^{26}$ prevê a adoção da letra padrão sem adição de marcas figurativas, restando, apenas, a marca nominativa em letra, cor e tamanho padrão.

Cabe destaque ao fato de que o ato explicitou, no item 28, que as marcas de cigarro estariam imunes de serem extintas pelo não-uso, caso tal caducidade seja decorrente da legislação de Plain Packaging ${ }^{27}$. Tal item será discutido à frente, em capítulo específico.

Ainda em 2011 a British American Tobacco e a Japan Tobacco entraram com ação ${ }^{28}$ contra o governo no Supremo Tribunal Australiano. A Phillip Morris Ltd. e a Imperial Tobacco juntaram-se ao caso, apoiando as demais empresas. O Cancer Council da Autralia apresentou submissões escritas, mas não foi admitido a intervir no processo. ${ }^{29}$

\footnotetext{
${ }^{26}$ AUSTRALIAN GOVERNMENT. Tobacco Plain Packaging Act 2011. Disponível em <http://www.comlaw.gov.au/Details/C2011A00148/Download>. Acesso em 11/04/2014. ${ }^{27}$ DAVIDSON, Mark. Plain Packaging of Tobacco and the "Right" to use a Trade Mark. Em European Intellectual Property Review, 2012. Disponível em < http://papers.ssrn.com/sol3/papers.cfm?abstract_id=2137455>. Acesso em 14 de maio de 2014. ${ }^{28}$ Casos de $n^{\circ}$ S389/2411 e S409/2011. HIGH COURT OF AUSTRALIA. British American Tobacco Australasia Limited and Ors v. The Commonwealth of Australia. Disponível em <http://www.hcourt.gov.au/cases/case-s389/2011>. Acesso em 01 de maio de 2014.

${ }^{29}$ RIMMER, Mathew. Cigarettes will kill you: The High Court of Australia \& plain packaging of tobacco products. Disponível em
} 
O setor fumageiro processou o governo australiano alegando que a legislação que adota o Plain Packaging viola os Direitos de Propriedade Intelectual garantidos constitucionalmente, havendo aquisição de propriedade do titular, em contrariedade ao artigo $51, \mathrm{XXXI}^{30}$ da Constituição Australiana ${ }^{31}$.

Cabe ressaltar que a BAT alegou ainda que as disposições da Lei do Plain Packaging constituiriam uma aquisição de propriedade da empresa que compreende não só as marcas, mas também as obras de direito autoral, patentes, desenho industrial e interferiria em seus licenciamentos ${ }^{32}$.

A Suprema Corte Australiana rejeitou os argumentos alegando que a constituição australiana confere proteção limitada à Propriedade Intelectual. Além disso, apesar de haver uma clara restrição, a Corte considerou não existir aquisição de propriedade, já que não haveria qualquer benefício auferido e, consequentemente, não haveria direito a indenização ${ }^{33}$.

A Corte destacou que há distinção entre uma tomada de propriedade e a aquisição, já que a tomada envolve a privação de propriedade a partir do ponto de vista de seu proprietário, enquanto a aquisição envolve mais do que a mera extinção de direitos, havendo benefícios econômicos para quem adquire.

Assim, a decisão que manteve o Plain Packaging na Australia versou sobre a aquisição de propriedade alegando que a mera tomada de propriedade não constitui expropriação, visto que não há benefício para o

<http://www.wipo.int/wipo_magazine/en/2013/01/article_0005.html>. Acesso em 01 de maio de 2014

${ }^{30} \mathrm{O}$ artigo 51, XXXI da Constituição Australiana dispõe: "The acquisition of property on just terms from any State or person for any purpose in respect of which the Parliament has power to make laws". PARLIAMENT OF AUSTRALIA. Commonwealth Of Australia Constitution Act. Disponível em

<http://www.aph.gov.au/About_Parliament/Senate/Powers_practice_n_procedures/ /link.aspx?_id $=$ F74707A5A4934E05A67EE5969B156435\&_Z=Z>. Acesso em 13 de maio de 2014.

${ }^{31}$ Casos de $\mathrm{n}^{\circ}$ S389/2411 e S409/2011. HIGH COURT OF AUSTRALIA. British American

Tobacco Australasia Limited and Ors v. The Commonwealth of Australia. Disponível em <http://www.hcourt.gov.au/cases/case-s389/2011>. Acesso em 01 de maio de 2014.

${ }^{32}$ HIGH COURT OF AUSTRALIA. JT International SA v Commonwealth of Australia [2012] HCA 43 (5 October 2012). Vide <http://www.austlii.edu.au/au/cases/cth/HCA/2012/43.html>. Acesso em 04 de maio de 2014.

${ }^{33}$ RIMMER, Mathew. Cigarettes will kill you: The High Court of Australia \& plain packaging of tobacco products. Op. Cit. 
adquirente, de modo que não há expansão dos seus direitos, interesses ou benefícios ${ }^{34}$.

Para justificar o argumento da expropriação, a indústria alegou que o governo australiano auferiu vantagem com a aquisição da propriedade das marcas. Argumentam, ainda, que a aquisição constitui uso/controle das embalagens de cigarro, já que pode-se retirar e colocar nela o que quiser.

Ao fim, ficou decidido que a legislação sobre marcas da Austrália não confere aos titulares de marcas a liberdade de usar a marca absolutamente livre de restrições provenientes de outras legislações, estando, então, o Plain Packaging Act de acordo com a Constituição Australiana. Desta forma, como já exposto, tal restrição constituiria tomada de propriedade e não aquisição/expropriação.

A decisão demonstra o entendimento da Corte de que a restrição não constitui uma aquisição da propriedade, mas uma restrição por meio de privação.

Tal decisão é emblemática e representa um possível sentido a ser seguido por outros tribunais em decisões decorrentes de processos contra legislações de Plain Packaging em outros países.

Cabe apontar, no entanto, a fragilidade da decisão no que consiste a Corte ter admitido uma tomada de propriedade sem indenização. Em alguns países, ao exemplo do Brasil, é possível que não seja admitida tal situação.

A questão da expropriação e indenização no Brasil será discutida em capítulo específico.

\section{II.2. Breve análise de Direito Comparado}

\footnotetext{
${ }^{34}$ HIGH COURT OF AUSTRALIA. JT International SA v Commonwealth of Australia [2012] HCA 43 (5 October 2012). Vide <http://www.austlii.edu.au/au/cases/cth/HCA/2012/43.html>. Acesso em 04 de maio de 2014.
} 
Uma previsão legal que proíbe certos comerciantes de utilizar as suas marcas viola os princípios de marcas e contradiz o direito de uso de uma marca registrada, garantidos por meio do Trade Marks Act Australiano. ${ }^{35} 36$

A Lei de Propriedade Industrial Brasileira (Lei 9297/96), da mesma forma, estabelece que o registro de marca assegura ao seu titular o seu uso exclusivo. $^{37}$

$\mathrm{O}$ artigo 51, XXXI da Constituição Australiana trata da desapropriação por parte do governo. Nos termos do artigo:

"51.The Parliament shall, subject to this Constitution, have power to make laws for the peace, order, and good government of the Commonwealth with respect to:

(xxxi.) The acquisition of property on just terms from any State or person for any purpose in respect of which the Parliament has power to make laws"

Assim, o Estado Australiano estaria autorizado a efetuar a aquisição da propriedade em "termos justos". Se o Plain Packaging for considerado uma aquisição de propriedade, esta deve ser feita nos termos do artigo 51, de forma que, provavelmente, seria necessária a indenização aos titulares dos registros ou pedidos de marcas de cigarro. Como visto no capítulo anterior, a Corte entendeu o plan packaging como uma mera tomada de propriedade que não constitui aquisição, de modo a não ser devida a indenização.

Para esclarecer a questão da aquisição da propriedade, o Plain Packagin Act deixou claro:

\footnotetext{
${ }^{35}$ INTA. Australia Tobacco Plain Packaging Bill 2011 Comments. Disponível em <http://www.inta.org/Advocacy/Documents/June32011.pdf>. Acesso em 28 de abril de 2014.

${ }^{36}$ O Trade Marks Act Australiano é a legislação do governo da Austrália que versa sobre marcas. $\mathrm{O}$ item 20 fala sobre os direitos garantidos pelo registro. AUSTRALIAN GOVERNMENT. Trade Marks Act 1995. Disponível em 〈http://www.comlaw.gov.au/Details/C2013C00143〉. Acesso em 28 de abril de 2014.

${ }^{37}$ Artigo 129 da referida lei: “Art. 129. A propriedade da marca adquire-se pelo registro validamente expedido, conforme as disposições desta Lei, sendo assegurado ao titular seu uso exclusivo em todo o território nacional, observado quanto às marcas coletivas e de certificação o disposto nos arts. 147 e 148."
} 


\section{"15 Acquisition of property}

(1) This Act does not apply to the extent (if any) that its operation would result in an acquisition of property from a person otherwise than on just terms.

(2) In particular, if, apart from this section, this Act would result in such an acquisition of property because it would prevent the use of a trade mark or other sign on or in relation to the retail packaging of tobacco products, or on tobacco products, then despite any other provision of this Act, the trade mark or sign may be used on or in relation to the retail packaging of tobacco products, or on tobacco products, subject to any requirements that may be prescribed in the regulations for the purposes of this subsection.

(3) To avoid doubt, any tobacco product requirement (within the meaning of paragraph (a) or (b) of the definition of tobacco product requirement) that does not result in such an acquisition of property continues to apply in relation to:

(a) the retail packaging of tobacco products; and

(b) the appearance of tobacco products."

A Constituição Brasileira trata de desapropriação no $\operatorname{artigo} 5^{\circ}$, de forma semelhante. In verbis:

"XXIV - a lei estabelecerá o procedimento para desapropriação por necessidade ou utilidade pública, ou por interesse social, mediante justa e prévia indenização em dinheiro, ressalvados os casos previstos nesta Constituição;"

O tema será tratado de forma aprofundada em capítulo próprio.

Assim como no Brasil, na Austrália existe um grande mercado ilegal de produtos de tabaco. O Plain Packaging pode configurar um risco de aumento na produção de produtos falsificados. Com as embalagens tão parecidas e sem distinção de marca, fica mais difícil identificar produtos ilegais. Assim, surge um grande potencial para falsificadores, já que será mais fácil produzir e reproduzir embalagens.

Tal fato não é somente negativo aos interesses dos titulares de marcas de cigarro, mas também aos consumidores e ao governo, já que são levados produtos de baixa qualidade ao mercado. Em outras palavras, a proposta de limitação do uso legítimo de marcas para padronizá-las é 
suscetível de aumentar o comércio de produtos falsificados. ${ }^{38}$

No Brasil, segundo dados da Secretaria da Receita Federal, o mercado ilegal corresponde a cerca de $29 \%$ do mercado brasileiro de cigarros. Este número envolve o contrabando, a falsificação e a comercialização sem o pagamento de todos os tributos ${ }^{39}$.

Desta forma, o mercado ilegal já constitui grande parcela do mercado de cigarros tanto no Brasil como na Austrália. As consequências concretas sobre a pirataria em torno dos produtos fumígenos, no entanto, só será avaliada com o caso concreto, após algum tempo de validade da medida.

\section{II.3. Argumentos dos dois pólos de interesse}

As entidades que defendem a introdução das embalagens genéricas afirmam que sua aplicação é indicada para diminuir a atratividade dos produtos de tabaco, principalmente entre crianças e jovens.

Isso porque a retirada dos elementos figurativos da embalagem faria com que a embalagem e o cigarro ficassem menos atrativos e, também, que as advertências ficassem mais visíveis e destacadas. Desta forma, haveria diminuição da captação de consumidores (principalmente jovens) ${ }^{40}$.

Além disso, afirmam as organizações que o uso de cores é também prejudicial aos consumidores. A utilização de cores como branco, bege, ouro e prata trariam a ideia de que os cigarros presentes em tal embalagem são menos nocivos, mais seguros e "lights", ou seja, de menor teor (usando

\footnotetext{
${ }^{38}$ INTA. Australia Tobacco Plain Packaging Bill 2011 Comments. Disponível em <http://www.inta.org/Advocacy/Documents/June32011.pdf>. Acesso em 28 de abril de 2014.

${ }^{39}$ SOUZA CRUZ. O mercado de cigarros. Disponível em

<http://www.souzacruz.com.br/group/sites/sou_7uvf24.nsf/vwPagesWebLive/DO7V9KNX?opend ocument\&SKN=2>. Acesso em 01 de maio de 2014.

${ }^{40}$ BONADIO, Enrico. Plain Packaging of Tobacco Products under EU Intellectual Property Law. Disponível em file://C:/Documents\%20and\%20Settings/Gelson/Meus\%20documentos/Downloads/SSRNid2174453.pdf >. Acesso em 14 de maio de 2014.
} 
inclusive esse tipo de descritores, sendo uma opção para parar de fumar ${ }^{41}$ ). Por outro lado, os cigarros em tons de vermelho seriam os mais fortes.

Há também o argumento de que a embalagem é o maior instrumento de marketing para as empresas de cigarro e, assim, ao remover a marca da embalagem, com seus logotipos e cores, aumenta-se a credibilidade e a lembrança das imagens de advertência nas embalagens, de modo a minimizar o potencial de passar ideias deturpadas aos consumidores das embalagens. $^{42}$

Argumenta-se também que a proibição total de publicidade é necessária para evitar que a indústria do tabaco se aproveite de lacunas das leis para fazer propaganda, como o cumprimento da lei que proíbe a publicidade do tabaco no ponto de venda ${ }^{43}$.

A base legal para alguns argumentos é a Convenção-Quadro para Controle do Tabaco, especificamente o artigo $13^{44}$, que versa sobre a proibição de toda a publicidade de produtos de tabaco. Já foi explicitado em capítulo anterior, no entanto, que tal dispositivo deve ser interpretado à luz da Constituição Federal e de seus princípios.

\footnotetext{
41 ACTBR. EMBALAGEM GENÉRICA DE PRODUTOS DE TABACO: PROTEGENDO CRIANÇAS, ADOLESCENTES E JOVENS DO MARKETING DA INDÚSTRIA DO TABACO. Disponível em <www.actbr.org.br/uploads/conteudo/738_embalagem_generica.pdf.> Acesso em 08/04/2014.

${ }^{42}$ ACTBR. Embalagem e informações para os consumidores nos maços de cigarros. Disponível em

$<$ http://www.google.com.br/url?sa=t\&rct=j\&q=\&esrc=s\&frm=1\&source=web\&cd=1\&ved=0CD MQFjAA\&url=http\%3A\%2F\%2Factbr.org.br\%2Fuploads\%2Fconteudo\%2F106_Embalagem-eInformacoes-Consumidores-Macos-de-

Cigarros.pdf\&ei=qgdHU8iPN66i0gHXtYDYAQ\&usg=AFQjCNE7H0Eg1HgZQ6vKajVkBhi7eK Ez7Q>. Acesso em 10/04/2014.

${ }^{43}$ ACTBR. Relatório da Pesquisa ITC Brasil sobre

Publicidade, Promoção e Patrocínio de Tabaco . Disponível em <actbr.org.br/uploads/conteudo/810_ITC_BRAZIL.pdf>. Acesso em 10 de abril de 2014.

${ }^{44}$ O artigo 13 da Convenção Quadro sobre o Controle do Tabaco destaca: "13. No mínimo, e segundo sua Constituição ou seus princípios constitucionais, cada Parte se compromete a: (a) proibir toda forma de publicidade, promoção e patrocínio do tabaco, que promova um produto de tabaco por qualquer meio, que seja falso, equivocado ou enganoso ou que possa induzir ao erro, a respeito de suas características, efeitos para a saúde, riscos e emissões;”. INCA. ConvençãoQuadro para o Controle do Tabaco. Disponível em <http://www2.inca.gov.br/wps/wcm/connect/5a3abd004eb68a22a09bb2f11fae00ee/Conven\%C3\% A7\% $3 \%$ A3o-

Quadro+para+o+Controle+do+Tabaco+em+portugu\%C3\%AAs.pdf?MOD=AJPERES\&CACHEI

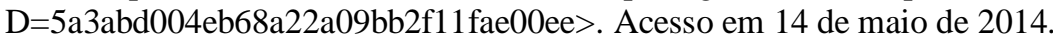


Quem é a favor da implementação das embalagens genéricas afima também que o argumento da indústria sobre o aumento do mercado ilegal é um mito, de modo que a proteção contra o contrabando depende de efetiva fiscalização por parte do governo. Além disso, a indústria do tabaco já se queixa atualmente do mercado ilegal $^{45}$. A questão do mercado ilegal, no entanto, é impossível de analisar com precisão, dado que depende muito da atuação do governo e da atuação concreta de falsificadores e do governo com o intuito de evitar a sua ocorrência.

Outro argumento é que evidências da Pesquisa ITC Brasil mostraram que fumantes e não-fumantes são extremamente favoráveis a regulamentações mais rigorosas para as empresas de tabaco (mais de 80\%) e que a embalagem genérica foi aprovada por quase metade dos fumantes (48,8\%). Outro estudo realizado com 640 mulheres brasileiras entre 16 e 26 anos relatou que as embalagens genéricas de cigarros foram classificadas como menos atraentes, com pior sabor e menos suaves na garganta que as embalagens com a marca ${ }^{46}$.

Um dos principais argumentos da indústria tabageira é que a introdução das embalagens genéricas é desproporcional e existem alternativas menos gravosas para alcançar resultados semelhantes.

Ao adotar medidas graves, devem-se ponderar as consequências em razão dos benefícios auferidos. Deve haver proporcionalidade na medida, como já citado anteriormente, ao ponto que a medida adotada seja a menos intrusiva possível para atingir o objetivo almejado.

$\mathrm{Na}$ situação apresentada, existem outras medidas que poderiam ser implementadas antes (ou no lugar) do Plain Packaging, de modo que não haja tantos prejuízos e violações. Uma delas, por exemplo, seria fazer valer

\footnotetext{
${ }^{45}$ ACTBR. EMBALAGEM GENÉRICA DE PRODUTOS DE TABACO: PROTEGENDO CRIANÇAS, ADOLESCENTES E JOVENS DO MARKETING DA INDÚSTRIA DO TABACO. Disponível em <www.actbr.org.br/uploads/conteudo/738_embalagem_generica.pdf.> Acesso em 08/04/2014.

${ }^{46}$ ACTBR. Relatório da Pesquisa ITC Brasil sobre Publicidade, Promoção e Patrocínio de Tabaco . Disponível em <actbr.org.br/uploads/conteudo/810_ITC_BRAZIL.pdf>. Acesso em 10 de abril de 2014
} 
a regulamentação já existente. A adoção de advertência na parte da frente dos maços (30\% da parte frontal) já foi estabelecida na Lei 12.546/2011, em seu artigo 49, §6 . Porém, apenas em 2016 tal medida será válida.

A colocação de advertências na parte da frente do maço de cigarro provavelmente será um fator determinante na diminuição do tabagismo no Brasil. Portanto, antes de fazer valer medidas muito restritivas, é uma opção razoável concretizar o que já existe.

A British American Tobacco citou como exemplos de medidas menos gravosas e que são eficientes para a diminuição do tabagismo a implementação de programas de educação direcionados a jovens, implementação de uma política fiscal consistente que mantenha o preço dos produtos de tabaco em níveis de impacto sobre a prevalência do tabagismo, aumentar medidas para prevenir o tráfico ilícito de tabaco, fazer valer as leis existentes que proíbem varejistas de vender cigarros para crianças e colocar avisos direcionados para resolver défices de informação ${ }^{47}$.

Ademais, além de haver possibilidade de intervenção menos gravosa, não há nenhuma evidência concreta de que a implementação do Plain Packaging efetivamente trará resultados ${ }^{48}$. Isto porque o único país a efetivamente utilizar o Plain Packaging o faz há pouquíssimo tempo, o que impossibilita uma pesquisa e análise concreta de sua eficácia.

Existem projetos de lei do tramitando no senado brasileiro tratando sobre Plain Packaging ${ }^{49}$, como se verá de forma aprofundada à frente. São dois projetos de texto praticamente idêntico, sendo que o primeiro deles foi arquivado por requerimento do autor do projeto. Neste primeiro projeto, o

\footnotetext{
${ }^{47}$ BRITISH AMERICAN TOBACCO - UK. UK standarised packaging consultation. Response of Brish American Tobacco UK Limited (08 August 2012). Disponível em <http://www.bat.com/group/sites/uk_9d9kcy.nsf/vwPagesWebLive/DO8WZC5E/\$FILE/medMD 8WZC6J.pdf > . Acesso em 14 de maio de 2014.

${ }^{48}$ PHILIP MORRIS. Executive summary of submission by Philip Morris (New Zealand) Limited to the Ministry of Health Consultation on Plain Packaging of Tobacco Products. Plain packaging of tobacco products will not reduce smoking rates, and will violate New Zealand's international trade obligations. New Zealand, 2012. Disponível em <http://www.pmi.com/eng/tobacco_regulation/submissions/Documents/Executive_Summary_of_P MNZ_submission_on_plain_packaging_final.pdf.>. Acesso em 14 de maio de 2014.

${ }^{49}$ Vide PLS 154/2012 e 103/2014. SENADO FEDERAL. Disponíveis em $<$ http://www.senado.gov.br/atividade/materia/Consulta_Parl.asp?RAD_TIP=PLS\&Tipo_Cons=15 $\&$ FlagTot=1\&p_cod_senador=4593\&p_cod_comissao=>. Acesso em 02 de maio de 2014.
} 
próprio autor da medida reconheceu que "Ainda que não existam estudos empíricos que comprovem o impacto da medida sobre as vendas e o consumo de produtos de tabaco, a violenta reação das companhias tabaqueiras a ela, em escala internacional, constitui forte indício de sua potencial efetividade"

Outro ponto levantado pela indústria é que as embalagens genéricas podem culminar em uma comoditização dos produtos de tabaco e gerar efeitos não-intencionais que iriam contra as próprias intenções da medida.

Um dos principais efeitos não-intencionais seria o aumento do já latente mercado ilegal. A partir do momento em que não há mais elementos marcários nas embalagens, aumenta-se a facilidade de comercialização de produtos de redes ilegais, que não arrecadam tributos e são mais acessíveis a menores de idade. Assim, haveria um risco aumentado de danos ao público a partir de um aumento no consumo de cigarro decorrente do aumento dos níveis de consumo de produtos ilícitos não regulamentados ${ }^{51}$.

Assim, há uma exposição do consumidor a produtos ilícitos que não passam por padrões de higiene e controle de qualidade de seus ingredientes, que podem ter seus teores elevados e maiores do que os cigarros legais.

Deve-se considerar ainda que todas as medidas que tornem mais fácil a falsificação também têm efeitos globais, uma vez que os lucros obtidos em um determinado mercado são susceptíveis de serem utilizados para aumentar os níveis de falsificação em outros países, independentemente da distância $^{52}$.

\footnotetext{
${ }^{50}$ SENADO FEDERAL. PLS 154/2012. Disponível em <http://www.senado.gov.br/atividade/materia/detalhes.asp?p_cod_mate=105567>. Acesso em 27 de março de 2014.

${ }^{51}$ BRITISH AMERICAN TOBACCO - UK. UK standarised packaging consultation. Response of Brish American Tobacco UK Limited (08 August 2012). Disponível em <http://www.bat.com/group/sites/uk_9d9kcy.nsf/vwPagesWebLive/DO8WZC5E/\$FILE/medMD 8WZC6J.pdf $>$. Acesso em 14 de maio de 2014.

${ }^{52}$ ABPI. ABPI's comments on the Australian Government Consultation Paper on Tobacco Plain Packaging. Disponível em <http://www.smoke-free.ca/plainpackaging/documents/2011/ABPI\%20-\%20Brazil.pdf>. Acesso em 01 de maio de 2014.
} 
Além disso, com a padronização das embalagens, o preço passa a ser o único elemento de identificação do produto, de forma que os consumidores provavelmente migrariam para os produtos mais baratos.

A redução significativa na diferenciação do produto por conta da embalagem genérica é passível de tornar os fumantes menos leais às suas marcas e cada vez mais leais ao preço ${ }^{53}$. Desta forma, a concorrência seria aumentada e os preços, de um modo geral, diminuídos, facilitando o acesso da população ao produto, o que vai de encontro à intenção de reduzir o tabagismo, tornando-os cada vez mais baratos e acessíveis para os consumidores, especialmente os mais jovens. Esta seria uma consequência não-intencional e contrária aos próprios objetivos da medida.

Ainda, tal comoditização de cigarros pode levar a um impasse na inovação, o que afeta negativamente a economia como um todo e afeta diversas empresas em diferentes ramos, tais como design e tecnologia. Isso demonstra a natureza das medidas solicitadas a serem implementadas ${ }^{54}$.

A indústria argumenta ainda que além do impacto sobre os preços, o Plain Packaging pode reduzir significativamente as oportunidades de entrada no mercado. Haveria pouca ou nenhuma possibilidade de entrar no mercado com um produto de uma nova marca, já que não haveria meios para indicar diferenças na qualidade e na origem dos produtos para os clientes que não conhecem esses produtos ${ }^{55}$.

Conclui-se, assim, que há argumentos válidos para todos os pólos de debate que, no entanto, devem ser ponderados de modo a encontrar medidas capazes de atingir os interesses em prol da saúde da população.

\footnotetext{
${ }^{53}$ BRITISH AMERICAN TOBACCO - UK. UK standarised packaging consultation. Response of Brish American Tobacco UK Limited (08 August 2012). Disponível em <http://www.bat.com/group/sites/uk_9d9kcy.nsf/vwPagesWebLive/DO8WZC5E/\$FILE/medMD 8WZC6J.pdf >. Acesso em 14 de maio de 2014.

${ }^{54}$ ABPI. ABPI's comments on the Australian Government Consultation Paper on Tobacco Plain

Packaging. Disponível em <http://www.smoke-free.ca/plainpackaging/documents/2011/ABPI\%20-\%20Brazil.pdf>. Acesso em 01 de maio de 2014.

${ }_{55}$ BRITISH AMERICAN TOBACCO - UK. UK standarised packaging consultation. Op. Cit.
} 


\section{PARTE II}

\section{CAPÍTULO III - Plain Packaging no Brasil}

No presente Capítulo buscar-se-á mostrar qual o contexto de aplicação do Plain Packaging no Brasil, bem como traçar uma análise geral das várias áreas que são atingidas pela instituição das referidas embalagens genéricas.

A inplementação do Plain Packaging no Brasil está tangenciada não somente pelas normas de direito público e pelos tratados internacionais, como já exposto, como está relacionada a diversos outros ramos do Direito.

Quanto ao Direito da Concorrência, é impossível determinar com certeza quais as consequências da medida, mas é latente que com a usurpação das marcas restringe-se a publicidade e, com isso, os produtos ficam muito parecidos e sem diferenciação; o que pode aumentar, ainda, a participação dos produtos ilegais no mercado.

Resta clara, também, a interferência que circunda o Direito Constitucional pela violação ao princípio da livre iniciativa e suas consequências no mercado, ao mesmo tempo em que o Código de Defesa do Consumidor trata da defesa da saúde e da segurança e, administrativamente, o Estado deve informar a sociedade sobre riscos e características do produto. Cada área será analisada adiante separadamente.

\section{III.1. Contexto das restrições de cigarro no Brasil}

No Brasil, a partir de 1988, iniciou-se um processo de conscientização em torno dos possíveis danos relacionados ao uso de 
produtos fumígenos. Inicialmente, tornou-se obrigatório o uso da frase: "O Ministério da Saúde adverte: fumar é prejudicial à saúde ${ }^{56 "}$ nas embalagens de cigarro e, desde então, cresceram as limitações à propaganda e as advertências.

Surgiu, então, a obrigação de comerciais de produtos derivados do tabaco serem veiculados somente entre as $21 \mathrm{~h}$ e as $6 \mathrm{~h}^{57}$, até que se torna proibida a propaganda de produtos derivados de tabaco em revistas, jornais, outdoors, televisão e rádios, sendo permitida somente a publicidade em pôsteres, painéis e cartazes, bem como o patrocínio de eventos culturais e esportivos e associar o fumo às praticas esportivas ${ }^{58}$.

Em 2001, a ANVISA determinou os teores máximos para alcatrão, nicotina e monóxido de carbono ${ }^{59}$ e as imagens de advertência passaram a ser obrigatórias em material de propaganda e embalagens de produtos fumígenos ${ }^{60}$.

Já em 2003 passou a ser obrigatório o uso das frases: "Venda proibida a menores de 18 anos" e "Este produto contém mais de 4.700 substâncias tóxicas, e nicotina, que causa dependência física ou psíquica. Não existem níveis seguros para consumo destas substâncias",61.

Por fim, em 2011, Lei Federal proíbe fumar em locais fechados ${ }^{62}$ e a ANVISA proíbe o uso de aditivos em produtos derivados do tabaco ${ }^{63}$.

$\mathrm{O}$ cuidado a ser tomado na análise regulatória deve perceber que vivemos uma onda regulatória em que as restrições não visam apenas a informar os consumidores, mas que podem possuir uma finalidade de

\footnotetext{
${ }^{56}$ Portaria n ${ }^{\circ} 490 / 88$ do Ministério da Saúde. Disponível em < http://bvsms.saude.gov.br/bvs/saudelegis/gm/1990/prt1050_08_08_1990.html >. Acesso em 14 de maio de 2014.

${ }^{57}$ Federal 9.294/96. Disponível em <http://www.planalto.gov.br/ccivil_03/leis/19294.htm〉. Acesso em 14 de maio de 2014.

${ }^{58}$ Vide Lei Federal 10.167/00. Disponível em <http://www.planalto.gov.br/ccivil_03/leis/L10167.htm>. Acesso em 14 de maio de 2014.

${ }^{59}$ RDC 46/01 da ANVISA.

${ }^{60}$ RDC $14 / 01$ da ANVISA.

${ }^{61}$ RDC $335 / 03$ da ANVISA.

${ }^{62}$ Lei Federal 12.546/2011. Disponível em <http://www.receita.fazenda.gov.br/Legislacao/leis/2011/lei12546.htm>. Acesso em 14 de maio de 2014.

${ }^{63}$ RDC 14/2012 da ANVISA.
} 
esvaziamento econômico de certas atividades produtivas, com a tentativa de inviabilizar a oferta e reduzir o consumo de determinados produtos, como o cigarro, aqui debatido ${ }^{64}$.

\section{III.2. Plain Packaging no Brasil}

A discussão sobre as embalagens genéricas no Brasil aumenta a cada ano. O Senado, por meio do projeto de lei $154 / 12^{65}$ tentou trazer a obrigatoriedade do Plain Packaging. Tal projeto é de autoria do Senador Rodrigo Rollemberg e foi arquivado, a pedido do próprio autor, em 17 de julho de 2013.

O mesmo senador propôs, em 2013, o projeto de lei 103/2014, com a mesma ementa. Os referidos projetos de lei têm como escopo alterar a Lei 9.294/1996, que dispõe sobre as restrições ao uso e à propaganda de produtos fumígenos (entre outros) com base no artigo 220 da Constituição Federal para "determinar que as embalagens e os maços de cigarros, cigarrilhas, charutos, fumo para cachimbo ou de qualquer outro produto derivado de tabaco não conterão dizeres, cores ou outros elementos gráficos além da marca do produto e da logomarca do fabricante, em letras em cor preta sobre fundo branco, e advertência sobre os malefícios do fumo, segundo frases estabelecidas por regulamento pelo Ministério da Saúde, acompanhada de imagens ou figuras que ilustrem o sentido da mensagem"

Ressalte-se que, na justificativa do projeto de lei 15 de 2012, o próprio autor reconheceu que ainda não existem estudos empíricos que comprovem a efetividade da medida.

\footnotetext{
${ }^{64}$ BINENBOJM, Gustavo. Asfixia Regulatória. Disponível em $<$ http://oglobo.globo.com/in/asfixia-regulatoria-2902104\#ixzz30TrIv8SF>. Acesso em 1 de maio de 2014.

${ }^{65}$ SENADO FEDERAL. PLS 154/2012. Disponível em

<http://www.senado.gov.br/atividade/materia/detalhes.asp?p_cod_mate=105567>. Acesso em 27 de março de 2014.

66 Ibid.
} 
O projeto de lei do senado 154 de 2012 foi arquivado, mas ainda está em tramitação o PLS 103 de 2013, com texto praticamente idêntico.

Os setores ligados a tabaco também discutem a questão da implementação do Plain Packaging no Brasil. O fato é que, conforme o crescimento da discussão sobre o assunto em diversos países cresce, maior a chance de uma possível implementação no Brasil, já que é um dos países mais engajados na busca pela diminuição do tabagismo.

\section{III.3. Relação com o Direito Constitucional}

A Constituição Federal protege a livre iniciativa, reconhecendo-a, em seu artigo $1^{\mathrm{o}^{67}}$, como direito fundamental. Em tal conceito estão incluídos, por exemplo, o direito do fabricante de se comunicar com o consumidor, e do consumidor receber informações do fabricante.

O Plain Packaging, invariavelmente, acaba por interferir na capacidade de comunicação entre fabricantes e consumidores de maneira desproporcional, decorrente da ingerência ilegítima nos direitos de livre iniciativa e manifestação dos fabricantes.

Ademais, o uso de embalagens genéricas afronta os direitos fundamentais de propriedade de marcas e outros signos distintivos, assegurados pelo artigo $5^{\circ}$, XXII e XXIX $^{68}$, da Constituição Brasileira. Nesse contexto, vai além e viola o inciso $\mathrm{XXIV}^{69}$, do mesmo artigo, visto que constitui verdadeira expropriação sem indenização.

\footnotetext{
67 “Art. $1^{\circ}$ A República Federativa do Brasil, formada pela união indissolúvel dos Estados e Municípios e do Distrito Federal, constitui-se em Estado Democrático de Direito e tem como fundamentos: (...) IV - os valores sociais do trabalho e da livre iniciativa;"

68 “Art. $5^{\circ}$ Todos são iguais perante a lei, sem distinção de qualquer natureza, garantindo-se aos brasileiros e aos estrangeiros residentes no País a inviolabilidade do direito à vida, à liberdade, à igualdade, à segurança e à propriedade, nos termos seguintes: (...)XXII - é garantido o direito de propriedade; (...)XXIX - a lei assegurará aos autores de inventos industriais privilégio temporário para sua utilização, bem como proteção às criações industriais, à propriedade das marcas, aos nomes de empresas e a outros signos distintivos, tendo em vista o interesse social e o desenvolvimento tecnológico e econômico do País;"

${ }^{69}$ Ainda no art. 5": "XXIV - a lei estabelecerá o procedimento para desapropriação por necessidade ou utilidade pública, ou por interesse social, mediante justa e prévia indenização em dinheiro, ressalvados os casos previstos nesta Constituição;"
} 
Além disso, a introdução do Plain Packaging representa, pela imposição de restrições a produtos e pela restrição à livre iniciativa, um entrave à livre circulação de mercadorias.

Por outro lado, a proteção à saúde é protegida pela Constituição sob o título de Direito Fundamental, eu seus artigos 6070 e 196 a 200: “Tal direito inclui, além de uma dimensão curativa, uma dimensão preventiva a ser concretizada pelos poderes públicos, o que sem dúvida se efetiva mediante a atividade informativa."71

Por fim, a Constituição Federal prevê, no artigo $220, \S 3^{\circ}$ e $4^{\text {o72 }}$, a defesa da informação e criação, competindo a lei federal estabelecer meios legais para defender a sociedade de propagandas de produtos que possam ser nocivos à saúde, bem como explicita que a propaganda de tabaco (entre outros produtos) estará sujeita a restrições legais.

Há uma contrariedade de princípios e, conforme se verá adiante, o equilíbrio deve se valer da busca por medidas alternativas que visem a proteção da saúde da sociedade sem tantos danos às empresas e seus direitos de propriedade intelectual.

\section{III.4. Relação com o Direito da Concorrência}

\footnotetext{
${ }^{70}$ Art. $6^{\circ}$ São direitos sociais a educação, a saúde, a alimentação, o trabalho, a moradia, o lazer, a segurança, a previdência social, a proteção à maternidade e à infância, a assistência aos desamparados, na forma desta Constituição.

${ }^{71}$ DIAS, Eduardo Rocha. "Direito à Saúde e Informação Administrativa. O caso das advertências relativas a produtos perigosos.” p. 19.

${ }^{72}$ Art. 220. A manifestação do pensamento, a criação, a expressão e a informação, sob qualquer forma, processo ou veículo não sofrerão qualquer restrição, observado o disposto nesta Constituição. (...)§ $3^{\circ}$ - Compete à lei federal: (...) II - estabelecer os meios legais que garantam à pessoa e à família a possibilidade de se defenderem de programas ou programações de rádio e televisão que contrariem o disposto no art. 221, bem como da propaganda de produtos, práticas e serviços que possam ser nocivos à saúde e ao meio ambiente. $\S 4^{\circ}$ - A propaganda comercial de tabaco, bebidas alcoólicas, agrotóxicos, medicamentos e terapias estará sujeita a restrições legais, nos termos do inciso II do parágrafo anterior, e conterá, sempre que necessário, advertência sobre os malefícios decorrentes de seu uso.
} 
A embalagem é, sem dúvida, uma das maiores fontes e atratividade de qualquer produto. No caso do cigarro tal assertiva é particularmente verdadeira, tendo em vista as inúmeras restrições de propaganda que já regulam o setor, como visto em capítulo anterior.

Pode-se citar, por exemplo, a impossibilidades de veiculação de propaganda em meios de massa, como TV e revistas, restando somente a chance de alguma comunicação no ponto de venda.

Em 2011, a lei 12.546 foi editada e a publicidade de produtos de tabaco passou a ser proibida na totalidade, com exceção, somente, da exposição de produtos no ponto de venda. ${ }^{73}$

Desta forma, restam poucas opções aos fabricantes para apresentar seu produto ao público e demonstrar as suas características. É neste cenário, então, que as embalagens ganham papel fundamental como principal elemento de publicidade da indústria fumageira.

Neste sentido, as empresas buscam passar, através das embalagens, conceitos profundos de personalidade para que o consumidor escolha qual marca se adapta ao seu gosto, identidade e, até mesmo, ao seu estilo de vida.

O cigarro é, então, um produto escolhido pelo consumidor com base na experimentação e na diferenciação das marcas e embalagens, tendo em vista que os preços são tabelados e não viabilizam a competição por conta de altas cargas tributárias ${ }^{74}$.

Assim, a publicidade tem papel indispensável no que tange a identificação da marca e a sua consolidação no mercado.

\footnotetext{
73 “Art. $3^{\circ}$ É vedada, em todo o território nacional, a propaganda comercial de cigarros, cigarrilhas, charutos, cachimbos ou qualquer outro produto fumígeno, derivado ou não do tabaco, com exceção apenas da exposição dos referidos produtos nos locais de vendas, desde que acompanhada das cláusulas de advertência a que se referem os §§ 2o, 3o e 4o deste artigo e da respectiva tabela de preços, que deve incluir o preço mínimo de venda no varejo de cigarros classificados no código 2402.20.00 da Tipi, vigente à época, conforme estabelecido pelo Poder Executivo."

${ }^{74}$ Para ilustração, o texto de JosÉ TAVARES DE ARAÚJO JR: "[O] poder de mercado nessa indústria [tabaco] advém de três fontes: o controle sobre os canais de distribuição, a fidelidade dos consumidores à marca, e as economias de escala nas atividades de publicidade e promoção de novas marcas". (JOSÉ TAVARES DE ARAÚJO JR., "Regulação da indústria de cigarros no Brasil" in Revista IBRAC, vol. 16, n.․ 2, p. 6).
} 
Além disso, como já visto neste estudo, o Plain Packaging pode gerar uma busca do consumidor pela marca mais barata, em vez de se fidelizar a uma marca.

Quando um produto novo é lançado, é preciso um investimento especialmente grande em publicidade (que, como visto, já é bastante restrita no setor fumageiro) para que o mesmo seja inserido no mercado com sucesso.

A entrada de qualquer produto no mercado já é geralmente um procedimento complitaco. No caso específico de produtos nocivos, como o cigarro, que possuem alta regulação por parte do governo, tal processo é ainda pior. E, se essa entrada no mercado já é complicada com vultosos investimentos em publicidade, sem ela se torna quase impossível diferenciar uma marca de outra, retirando do processo competitivo uma etapa fundamental.

Sem a diferenciação por meio da marca na embalagem do cigarro retira-se a diferenciação com base em publicidade, o que traz a questionamento qual seria a nova dinâmica adotada pelo setor.

É impossível prever exatamente quais serão as consequências e como o consumidor e o mercado irão se comportar. No entanto, é possível que a retirada da marca (e consequentemente da publicidade) leve a uma estabilidade entre os consumidores, que manterão a escolha de marca de cigarro que já lhe é habitual, sem uma oscilação e experimentação de novos produtos. No entanto, o contrário também é plausível, como já foi observado: com as embalagens igualadas, é possível que o consumidor passe a eleger a sua marca de cigarro com base exclusivamente no preço.

Deve-se ressaltar que há a possibilidade de que a retirada das marcas na embalagem amplie o mercado para empresas de menor porte, que possivelmente já não faziam investimentos em propaganda e publicidade, que terão seus produtos igualados, ao menos no que tange as embalagens, aos cigarros das grandes empresas que dominam atualmente o mercado. 
Tal aproximação das embalagens de toda e qualquer empresa, independente de seu porte financeiro, leva a uma outra questão importante: a pirataria. Como já estudado, as embalagens genéricas podem trazer um aumento no mercado ilegal por conta da facilidade em produzir e reproduzir embalagens.

\section{III.5. Relação com o Direito Administrativo}

O Estado exerce grande influência sobre a difusão de informações e, consequentemente, sobre as escolhas da sociedade. Assim, ao realizar essa função, o Estado se torna um detentor e ativo redistribuidor do saber e das competências.

O Estado, através do poder de polícia, atua de forma a proteger o princípio da supremacia do interesse público sobre o interesse privado. Por meio deste controle, ele protege a sociedade de condutas particulares, restringindo direitos dos indivíduos, com a intenção de evitar danos maiores à coletividade.

Em outras palavras, pode-se conceituar o poder de polícia como "a prerrogativa de direito público que, calcada na lei, autoriza a Administração Pública a restringir o uso e gozo da liberdade e da propriedade em favor do interesse da coletividade ${ }^{75,}$.

A regulação por meio da obrigatoriedade de advertências nas embalagens é, por exemplo, uma aplicação do poder de polícia do Estado. Nesse contexto, temos que a privação do uso de uma marca em razão do suposto bem estar geral da sociedade consiste num ato de poder de polícia (e, portanto, lícito) por parte do Estado.

A supremacia do interesse público, no entanto, "em um contexto de um Estado Democrático de Direito, que decorre da Constituição, deixar de vincular o interesse público ao cumprimento dos fins e valores maiores 
previstos na Carta Magna, evitando uma aplicação equivocada do princípio e sua vinculação a elementos autoritários ${ }^{76,}$ (Dias, 2008, p.270).

Cabe definir que o interesse público é a reunião de interesses de uma coletividade e que, portanto, pode ser contraditório. Deve haver impessoalidade por parte do Poder Público. Como identificar, então, quais os interesses da coletividade? Para tal, é necessário respeitar e proteger os direitos fundamentais como, por exemplo, a livre iniciativa e a liberdade. Desta forma, a implementação do Plain Packaging pode vir a ser um ato proveniente do poder de policia que busca um suposto interesse da coletividade que foi pressuposto de maneira ineficaz.

Ademais, há que se levar em consideração outros princípios gerais de Direito Administrativo. Primeiramente, o principio da igualdade pode ser violado quando há discriminação na regulação de um setor específico em detrimento de outros, injustificadamente. Da mesma forma, viola-se o principio da impessoalidade, prevista no caput do artigo $37^{77}$ da Constituição Federal.

A aplicação do princípio da proporcionalidade é fundamental para que exista uma ponderação entre a medida proposta, seus efeitos concretos e consequências, delimitando o limite entre a atuação legítima e o excesso de poder. O Poder Público deve atuar "porque a situação reclama realmente a intervenção e esta deve processar-se com equilibro, sem excessos e proporcionalmente ao fim a ser atingido ${ }^{78,}$.

Como já visto, deve ser feita uma análise de proporcionalidade da medida a ser introduzida, que envolve um julgamento de adequação da medida para alcançar a finalidade para que se destina.

Ressalte-se, neste ponto, que a medida das embalagens genéricas interfere nos direitos de propriedade e na liberdade econômica deste ramo

\footnotetext{
${ }^{76}$ DIAS, Eduardo Rocha. Direito à Saúde e Informação Administrativa. O caso das advertências relativas a produtos perigosos. p. 270.

77 “Art. 37. A administração pública direta e indireta de qualquer dos Poderes da União, dos Estados, do Distrito Federal e dos Municípios obedecerá aos princípios de legalidade, impessoalidade, moralidade, publicidade e eficiência (...)"

${ }^{78}$ CARVALHO FILHO, José dos Santos. Manual de Direito Administrativo.p. 44
} 
de produtos. Assim, pode não ser proporcional a aplicação de uma medida tão restritiva sobre um produto lícito e que já possui diversas restrições. Existem medidas menos gravosas (e mais proporcionais) a fim do que se pretende atingir.

No mesmo sentido, destaca-se o princípio da eficiência, explicitado também no caput do artigo 37 da Constituição Federal, na atuação do Estado, que defende a produtividade do Estado da forma menos onerosa e custosa possível. Não existem, no entanto, estudos que comprovem a efetividade do Plain Packaging (e na prática ainda não se pode auferir resultados, já que é medida recente na Australia), de modo que sua implementação seria absurdamente custosa aos particulares titulares das marcas, ao país e ao próprio governo, já que podem ocorrer diversas violações de ordem constitucional, de tratados internacionais e de direitos de propriedade, além de consequências não intencionais que tem efeitos contrários aos que se desejam.

\section{III.6. Relação com o Direito do Consumidor}

Na sociedade em que vivemos, pautada na publicidade, a propaganda induz ao consumo pela criação de uma necessidade. "O abuso na veiculação de mensagens publicitárias, por sua vez, pode servir como estímulo à aquisição de produtos que causam dependência ou que geram danos à saúde, o que exige dos poderes públicos a adoção de medidas destinadas a proteger referido bem jurídico". 79

O Estado possui, então, prerrogativa para informar e proteger o consumidor. No caso de produtos de cigarro o Estado já o faz, por meio do banimento de propagandas além do ponto de venda, da proibição de aditivos e, principalmente, das advertências nas embalagens.

\footnotetext{
${ }^{79}$ DIAS, Eduardo Rocha. Direito à Saúde e Informação Administrativa. O caso das advertências relativas a produtos perigosos. p. 19.
} 
Ocorre que, com a aderência ao Plain Packaging, a ausência de qualquer elemento figurativo pode gerar confusão ao consumidor, tendo em consideração que as embalagens serão idênticas e se aproximarão também das embalagens de produtos ilegais.

Há, também aqui, um conflito de princípios e normas. Apesar de já haver proteção do Estado por meio das várias restrições aos produtos derivados do tabaco, o Código de Defesa do Consumidor legitima a postura protecionista do Estado em seu artigo 10, ao determinar que "O fornecedor não poderá colocar no mercado de consumo produto ou serviço que sabe ou deveria saber apresentar alto grau de nocividade ou periculosidade à saúde ou segurança".

Além disso, o artigo $6^{\circ}$, III $^{80}$, versa sobre o direito do consumidor a informação adequada e clara sobre os riscos que o produto apresente e no artigo $8^{\mathbf{0} 81}$, obriga os fornecedores a dar as informações necessárias e adequadas a respeito de produtos e serviços que acarretam riscos à saúde e à segurança dos consumidores.

No mesmo sentido, o artigo $9^{\mathbf{8} 2}$ fala sobre o dever de informar a respeito da nocividade sem prejuízo da adoção de outras medidas cabíveis em cada caso concreto (o que pode incluir as embalagens genéricas).

Assim, temos, de um lado, os direitos básicos do consumidor e o dever de informação por parte do fornecedor e, do outro, a possibilidade da confusão do consumidor diante de produtos idênticos, bem como a proximidade de produtos ilícitos provenientes do mercado ilegal.

\section{III.7. Relação com o Direito da Propriedade Intelectual}

\footnotetext{
80 “ Art. $6^{\circ}$ São direitos básicos do consumidor: (...)III - a informação adequada e clara sobre os diferentes produtos e serviços, com especificação correta de quantidade, características, composição, qualidade, tributos incidentes e preço, bem como sobre os riscos que apresentem;" 81 “Art. $8^{\circ}$ Os produtos e serviços colocados no mercado de consumo não acarretarão riscos à saúde ou segurança dos consumidores, exceto os considerados normais e previsíveis em decorrência de sua natureza e fruição, obrigando-se os fornecedores, em qualquer hipótese, a dar as informações necessárias e adequadas a seu respeito."

82 “Art. $9^{\circ} \mathrm{O}$ fornecedor de produtos e serviços potencialmente nocivos ou perigosos à saúde ou segurança deverá informar, de maneira ostensiva e adequada, a respeito da sua nocividade ou periculosidade, sem prejuízo da adoção de outras medidas cabíveis em cada caso concreto."
} 
A lei 9279/96 (Lei da Propriedade Industrial) conceitua, em seu artigo 123, a marca como "aquela usada para distinguir produto ou serviço de outro idêntico, semelhante ou afim, de origem diversa".

A marca pode, portanto, ser nominativa (apenas o nome), mista (nome estilizado) ou figurativa (somente desenho sem o elemento nominativo).

O registro da marca no Instituto Nacional da Propriedade Industrial dá ao titular o direito de utilizar sua marca nos produtos ou serviços para os quais foi solicitado o registro, bem como impedir terceiros de usá-la.

A introdução do Plain Packaging constitui uma privação dos direitos e propriedade intelectual dos titulares de marcas registradas que as utilizam nas embalagens. Além disso, ressalte-se que ocorre uma violação aos direitos intangíveis relacionados à marca, devido ao seu valor comercial.

A subtração de tal bem é ilegal, a menos que justificada e, ainda que haja justificativa plausível, só é legítima se acompanhada de indenização pela privação de direitos. Há necessidade de definir se a subtração que ocorre em decorrência do Plain Packaging é uma expropriação. O tema será amplamente debatido no capítulo seguinte, em espaço apropriado. 


\section{CAPÍTULO IV - As consequências da restrição na Propriedade Intelectual}

No presente Capítulo buscar-se-á delinear os efeitos da utilização das embalagens genéricas nos direitos de propriedade intelectual dos titulares de marcas da indústria do tabaco.

\section{IV.1. Prejuízos à função de marca}

Como visto no capítulo anterior, o registro de uma marca dá ao seu titular o direito de utilizá-la para os produtos ou serviços para os quais foi solicitado o registro, bem como impedir terceiros de usá-la.

Embora seja permitido utilizar os elementos nominativos registrados nas embalagens, com o Plain Packaging há o impedimento de utilizar qualquer outro elemento das marcas registradas.

Assim, as marcas figurativas perdem o valor, já que não podem ser utilizadas na embalagem de nenhuma maneira, e as marcas mistas também também são enfraquecidas.

Como já foi visto em capítulo anterior, o direito à propriedade de marcas constitucionalmente garantido é violado pela instituição do Plain Packaging. Grande parte do valor investido em ativos intelectuais é perdido em embalagens vazias de conteúdo.

O Plain Packaging faz com que uma das funções primordiais da marca seja perdida. A função de identificação da origem do produto é enfraquecida com a retirada de todos os elementos além do nominativo.

As marcas servem, também, para distinguir um de bem de outro; simbolizam a qualidade do produto, a boa vontade e reputação do fabricante do produto e promove a inovação. Regulamentações que limitam ou proíbem a utilização elementos figurativos, cores ou outros elementos destinados a diferenciar um produto dos de seus concorrentes exclui a 
possibilidade de a marca de cumprir as suas principais funções e reduz os incentivos do fabricante para investir em qualidade e em novos produtos ${ }^{83}$.

A perda de tais funções essenciais afeta os consumidores de forma direta. Ao escolher um produto, o consumidor é capaz de distinguir produtos e serviços de diferentes empresas com base na embalagem. Assim, sem a marca completa e com a padronização de todas as embalagens da indústria do tabaco, o Plain Packaging pode fazer com que a capacidade de distinguir produtos de diferentes origens seja afetada, já que não haveria muita diferença entre as embalagens de cigarro vendidas por diferentes empresas. ${ }^{84}$ Desta forma, pode haver confusão sobre a origem e sobre a qualidade do produto.

A dificuldade em distinguir os produtos faz com que até nãofumantes sejam prejudicados. Varejistas e distribuidores perderiam um tempo considerável ao procurar alguma marca específica para fornecer ao consumidor.

Ademais, a embalagem padronizada faz com que a marca perca a função de passar mensagens de cunho psicológico - que vem a ser justamente um dos principais argumentos de quem defende a sua implementação - já que, em mercados onde produtos ou serviços tendem a ser homogêneos e padronizados, a escolha se dá pela imagem da marca. ${ }^{85}$

Cabe brevemente destacar que o Plain Packaging também afeta registros de patentes e design. A termo de exemplo, o número de patentes e designs da BAT no Reino Unido é de aproximadamente 160 e 150 . Desta forma, esses registros e pedidos de registro correspondem a um vasto

\footnotetext{
${ }^{83}$ ECONOMIESUISSE. Intellectual Property violations resulting from excessive packaging restrictions. Disponível em

$<$ http://www.google.com.br/url?sa=t\&rct=j\&q=\&esrc=s\&frm $=1 \&$ source=web\&cd=1\&cad=rja\&u act $=8 \&$ ved $=0 \mathrm{CC} 8 \mathrm{QFjAA} \&$ url $=\mathrm{http} \% 3 \mathrm{~A} \% 2 \mathrm{~F} \% 2 \mathrm{Fwww}$. smoke-free.ca $\% 2$ Ftrade-andtobacco\%2FResources\%2Findustryfriendly\%2FEconomiesuisse_position_paper_on_Generic_Lab elling_November_2009.pdf\&ei=T-pzU9HfHrG-sQSZmoHYCg\&usg=AFQjCNH3n8KJejUGClCIjSTuVCgHWKmSg\&bvm=bv.66917471,d.cWc>. Acesso em 14 de maio de 2014. ${ }^{84}$ BONADIO, Enrico. Plain Packaging of Tobacco Products under EU Intellectual Property Law. Disponível em file:///C:/Documents\%20and\%20Settings/Gelson/Meus\%20documentos/Downloads/SSRNid2174453.pdf >. Acesso em 14 de maio de 2014. ${ }^{85} \mathrm{Ibid}$
} 
investimento financeiro. Tais direitos seriam prejudicados e possivelmente expropriados pelo Plain Packaging, de modo a ser devida uma compensação significativa, que deve ser determinada por meio de cálculo complexo $^{86}$.

\section{IV.2. Plain Packaging: Expropriação marcaria?}

No caso da implementação do Plain Packaging há uma restrição de uso aos titulares das marcas de cigarros. Deste modo, como já visto, para que tal medida seja autorizada, é necessário que haja um teste de proporcionalidade da medida, de modo que seja posto em análise o objetivo que se pretende atingir e as consequências negativas de tal ato.

Como já visto, a Constituição Brasileira trata de desapropriação no artigo $5^{\circ}$, de forma a autorizá-la desde que feita acompanhada de indenização justa, prévia e em dinheiro. Assim, caso o Plain Packaging seja considerado como uma forma de expropriação deve vir acompanhada de tais requisitos.

Por outro lado, existe entendimento de que a indenização deve ser feita com base na responsabilidade objetiva do Estado, explicitada no art. $37, \S 6^{\circ}$ da Constituição Federal. In verbis:

"Há duas espécies de desapropriação indireta: o esbulho possessório do bem por parte do Estado seguido da sua afetação a serviços públicos (...) e a decorrente de condicionamentos legais ou administrativos à propriedade (ex: lei ou regulamento que proíba o desmatamento de cem por cento em uma área pertencente a particulares - desapropriação indireta regulatória).

As primeiras serão sempre ilícitas, e as segundas poderão ser ou não ser constitucionais, sobretudo à luz do atendimento ou não ao princípio da proporcionalidade. Mas em ambas as hipóteses geram direito à indenização.

Em ambos os casos o fundamento da indenização devida ao particular não é o artigo $5^{\circ}$, XXIV, CF (justa indenização pela desapropriação), mas sim o art. $37, \S 6, \mathrm{CF}$ (responsabilidade

\footnotetext{
${ }^{86}$ BRITISH AMERICAN TOBACCO - UK. UK standarised packaging consultation. Response of Brish American Tobacco UK Limited (08 August 2012). Disponível em http://www.bat.com/group/sites/uk_9d9kcy.nsf/vwPagesWebLive/DO8WZC5E/\$FILE/medMD8 WZC6J.pdf Acesso em 14 de maio de 2014.
} 
objetiva do Estado), que (...) pode ser desencadeada por comportamentos estatais ilícitos ou lícitos/constitucionais." 87 Grifei.

Deste trecho, retiram-se duas informações importantes para o presente caso concreto: um que existe a possibilidade de indenização no direito brasileiro mesmo quando não se caracteriza expressamente requisito de desapropriação, sendo possível utilizar a base da responsabilidade civil do Estado.

Assim, mesmo que haja uma previsão num possível texto legal brasileiro de que o Plain Packaging não constitui desapropriação - como fez o Plain Packaging Act da Australia - ainda assim há possibilidade de indenização pelo argumento da responsabilidade.

Além disso, destaca-se que para a medida de desapropriação ser constitucional, deve ser atendido o princípio da proporcionalidade, como já explicito em capítulo anterior. O teste da proporcionalidade deve considerar se a medida possui consequências negativas que compensem os seus benefícios.

Em seguida, Aragão completa que:

"(A desapropriação indireta) Dá-se através da instituição de uma suposta limitação administrativa à propriedade que, ao contrário do que determinaria a sua natureza, acaba por retirar o conteúdo econômico do bem.

Se a norma ou ato for inconstitucional (...) o direito à indenização será indiscutível e não excluirá o retorno ao status quo ante. $\mathrm{O}$ problema será se a norma ou ato restritivo for constitucional (...). A chave para a indenizabilidade (...) serão a especificidade e a anormalidade da limitação em relação às faculdades inerentes ao direito de propriedade. Em outras palavras, para a restrição lícita ser indenizável ela tem que ser específica em relação a um ou alguns dos cidadãos, e não dirigida difusamente a toda a sociedade; e anormal, no sentido de não decorrer das limitações já inerentes à viabilização da vida em sociedade.

Nesses casos, o prejuízo do particular, em razão da legitimidade dos condicionamentos impostos, por mais intensos que sejam, se resolverá sempre apenas em indenização, nunca pelo retorno ao status quo ante. ${ }^{, 88}$

\footnotetext{
${ }^{87}$ ARAGÃO, Alexandre Santos de. Curso de Direito Administrativo.p. 267 e seguintes.

${ }^{88}$ Ibid. p. 269 e seguintes.
} 
É provável que com a implementação do Plain Packaging no Brasil, da mesma forma que ocorreu na Australia, algumas ações questionando a constitucionalidade da medida sejam propostas. Do trecho acima, aproveitase para o presente caso que, independentemente da decisão de uma possível ação, é plausível que haja indenização das empresas. Isto porque, conforme exposto, em sendo considerada inconstitucional, a medida de certo geraria indenização e retorno ao status quo ante.

Se a medida for considerada constitucional e lícita, deve-se analisar a especificidade e normalidade. Ao que parece, um medida restritiva que é imposta a um único ramo e a específicas empresas não é uma medida difusa a toda a sociedade e normal. Desta forma, se assim considerada, seria devida indenização pelo Estado aos particulares, no entanto, sem retorno ao status quo ante.

Conclui-se, então, que para além da análise de proporcionalidade, é provável que caiba uma indenização aos titulares de marcas prejudicados que terão o uso de suas marcas limitado pela medida do Plain Packaging.

Ressalte-se que na decisão da Corte Australiana, destacou-se que a quantia necessária para indenizar os proprietários e compensar a tomada de propriedade seria tão grande que a possibilidade de evasão não pode ser evitada. No entanto, como o Plain Packaging Act não faz referência ao "justo termo" de compensação, houve uma escolha para proteger a saúde pública em detrimento da compensação aos proprietários.

\section{IV.3. Caducidade da marca expropriada}

Ao determinar a proibição do uso de elementos figurativos na embalagem, os titulares são privados do uso de suas marcas.

No Tobacco Plain Packaging Act of 2011, ficou explícito que as marcas de cigarro estariam imunes de serem extintas pelo não-uso, no caso de tal caducidade ser decorrente da legislação de Plain Packaging. Nos termos do referido documento: 


\section{Effect on the Trade Marks Act 1995 of non-use of trade mark as a result of this Act}

(1) For the purposes of the Trade Marks Act 1995, and regulations made under that Act, an applicant for the registration of a trade mark in respect of tobacco products is taken to intend to:

(a) use the trade mark in Australia in relation to those products; or

(b) authorise another person to use the trade mark in Australia in relation to those products; or

(c) assign the trade mark to a body corporate that is about to be constituted with a view to the body corporate using the trade mark in Australia in relation to those products;

if the applicant would intend to do so but for the operation of this Act.

(2) To avoid doubt, for the purposes of paragraph 42(b) of the Trade Marks Act 1995, this Act does not have the effect that the use of a trade mark in relation to tobacco products would be contrary to law.

(3) To avoid doubt, for the purposes of sections 38 and 84A of the Trade Marks Act 1995, and regulations 17A.27 and 17A.42A of the Trade Marks Regulations 1995:

(a) the operation of this Act; or

(b) the circumstance that a person is prevented, by or under this Act, from using a trade mark on or in relation to the retail packaging of tobacco products, or on tobacco products;

\section{are not circumstances that make it reasonable or} appropriate:

(c) not to register the trade mark; or

(d) to revoke the acceptance of an application for registration of the trade mark; or

(e) to register the trade mark subject to conditions or limitations; or

(f) to revoke the registration of the trade mark.

(4) For the purposes of paragraph 100(1)(c) of the Trade Marks Act 1995, an opponent is taken to have rebutted an allegation if the opponent establishes that the registered owner would have used the trade mark in Australia on or in relation to the retail packaging of tobacco products, or on tobacco products, but for the operation of this Act. ${ }^{89}$

${ }^{89}$ AUSTRALIAN GOVERNMENT. Tobacco Plain Packaging Act 2011. Disponível em <http://www.comlaw.gov.au/Details/C2011A00148/Download>. Acesso em 11/04/2014. 
Essa é uma previsão importante caso o Plain Packaging venha a ser concretizado no Brasil. A Lei 9279/96 ${ }^{90}$, em seu artigo 143, deixa claro que as marcas serão extintas por caducidade quando "o uso da marca tiver sido interrompido por mais de 5 (cinco) anos consecutivos, ou se, no mesmo prazo, a marca tiver sido usada com modificação que implique alteração de seu caráter distintivo original, tal como constante do certificado de registro."

$\mathrm{O}$ uso da marca com a sua forma somente nominativa faz com que diversas marcas registradas, se mistas, sejam utilizadas de forma diferente do constante no registro no INPI, ou ainda, que sejam consideradas como não utilizadas. Assim, estaria a situação enquadrada em tal artigo, possibilitando a extinção.

Por outro lado, a mesma lei diz que não ocorrerá caducidade se o titular justificar o desuso da marca por razões legítimas. Desta forma, seria considerada como razão legítima a falta de uso por conta de legislação que determina a utilização do Plain Packaging no país? É bastante provável que sim, de modo que não haveria caducidade de marca por conta do uso diferente em embalagens. No entanto, é impossível prever o posicionamento do INPI e dos tribunais quanto a este ponto.

Consta também, no artigo $19^{91}$ do TRIPS, a previsão de que não haverá caducidade se houver razão legítima para o não uso por parte do titular. Desta forma, o mesmo entendimento sobre o instituto no Brasil demonstrado a cima pode ser estendido aos outros países que fazem parte do presente tratado.

\section{IV.4. Marca: direito positivo e negativo ou só negativo?}

\footnotetext{
${ }^{90}$ Lei Federal 9.279/96. Disponível em <http://www.planalto.gov.br/ccivil_03/leis/L9279.htm>. Acesso em 12 de abril de 2014.

91 “Artigo 19: 1. Se sua manutenção requer o uso da marca, um registro só poderá ser cancelado após transcorrido um prazo ininterrupto de pelo menos três anos de não-uso, a menos que o titular da marca demonstre motivos válidos, baseados na existência de obstáculos a esse uso. Serão reconhecidos como motivos válidos para o não-uso circunstâncias alheias à vontade do titular da marca, que constituam um obstáculo ao uso da mesma, tais como restrições à importação ou outros requisitos oficiais relativos aos bens e serviços protegidos pela marca.”
} 
A WTO $^{92}$ (World Trademark Organization) se posicionou no sentido de que não existe direito positivo de uso de marca. Além disso, não há referência expressa na CUP e no TRIPs no sentido de que existe tal direito positivo de utilizar a marca. O direito conferido pelo TRIPS é de prevenir que terceiros utilizem a sua marca, e não direito de uso (art. 16) ${ }^{93}$.

Da mesma forma se posicionou o governo australiano ao decidir sobre a legalidade do Plain Packaging. O governo alegou que a legislação de propriedade intelectual não confere direito positivo, mas apenas negativo para impedir o uso por terceiros, de modo a excluir outros, apesar de que o item 20 da Lei de Marcas Australiana prevê, além disso, o direito de usar a marca $^{94}$.

Assim, se a marca for considerada como revestida de direito negativo de uso, essa função estaria mantida, já que os titulares ainda seriam aptos a impedir que terceiros utilizem sua marca.

Caso o direito de marca seja considerado como direito positivo, o fato de permitir o registro de uma marca, mas impedir o seu uso de forma completa aniquilaria todo o sentido do registro, que é o de uso exclusivo da marca. ${ }^{95}$

\section{IV.5. Posição das entidades de Propriedade Industrial sobre o tema}

Algumas entidades internacionais de Propriedade Intelectual já se manifestaram sobre o conceito e consequências do Plain Packaging.

\footnotetext{
${ }^{92}$ A WTO (OMC, em português) é uma organização internacional que trata das regras globais de comércio entre as nações. Sua principal função é garantir os fluxos de comércio o mais livremente possível. Vide <http://www.wto.org/index.htm>. Acesso em 14 de maio de 2014.

${ }^{93}$ DAVIDSON, Mark. Plain Packaging of Tobacco and the "Right" to use a Trade Mark. Em European Intellectual Property Review, 2012. Disponível em < http://papers.ssrn.com/sol3/papers.cfm?abstract_id=2137455>. Acesso em 14 de maio de 2014. 9494 HIGH COURT OF AUSTRALIA. JT International SA v Commonwealth of Australia [2012] HCA 43 (5 October 2012). Vide <http://www.austlii.edu.au/au/cases/cth/HCA/2012/43.html>. Acesso em 04 de maio de 2014.

${ }^{95}$ BONADIO, Enrico. Plain Packaging of Tobacco Products under EU Intellectual Property Law. Disponível em file://C:/Documents\%20and\%20Settings/Gelson/Meus\%20documentos/Downloads/SSRNid2174453.pdf >. Acesso em 14 de maio de 2014.
} 
A INTA (International Trademark Association) ${ }^{96}$ se posicionou, em alguns documentos oficiais ${ }^{97}$ no sentido de que, apesar de apoiar os esforços do governo australiano na busca por medidas no sentido de melhorar a saúde pública ${ }^{98}$, entende que o Plain Packaging, por meio do "Tobacco Plain Packaging Bill 2011"99 pode ser uma séria invasão aos direitos de marcas de titulares de marcas de tabaco e frustra a habilidade das marcas de funcionar propriamente de um comércio livre e efetivo. Ademais, entende que o efeito do Plain Packaging seria equivalente a uma invalidação das marcas, além de afetar substancialmente o seu valor em detrimento de seus titulares. ${ }^{100}$

A INTA defende ainda que o Plain Packaging viola obrigações decorrentes de tratados internacionais e aumenta o risco de contrabando, bem como se mostrou preocupada com o efeito da medida na distintividade das marcas e seus registros. ${ }^{101}$

Já a ASIPI (Associação Interamericana da Propriedade Intelecual) ${ }^{102}$, indica também ilegalidade da medida por conta da violação ao artigo 20 do TRIPS (ônus injustificado, já exposto em capítulo anterior) e a desproporcionalidade do Plain Packaging. Isto porque a embalagem genérica constitui uma verdadeira destruição das marcas, com o fim de informar algo que os consumidores já sabem - que o cigarro faz mal - de

\footnotetext{
${ }^{96}$ A INTA é uma associação global de titulares de marcas e de profissionais dedicados ao apoio às marcas e à propriedade intelectual a elas associada, que visa proteger os consumidores e promover o comércio justo e eficaz. Vide <http://www.inta.org/pt/Pages/Home.aspx > . Acesso em 27 de abril de 2014

${ }^{97}$ Disponíveis em <http://www.inta.org/Search/SearchResults.aspx?k=plain\%20packaging > Acesso em 27 de abril de 2014.

${ }^{98}$ INTA. INTA_Public consultation TPD_comments re Plain Packaging . Disponível em <http://www.inta.org/PDF\%20Library/INTA_Public\%20consultation\%20TPD_comments\%20re\% 20plain\%20packaging.pdf $>$ Acesso em 28 de abril de 2014.

99 AUSTRALIAN GOVERNMENT. Tobacco Plain Packaging Act 2011. Disponível em <http://www.inta.org/Advocacy/Documents/June32011.pdf>. Acesso em 28 de abril de 2014.

${ }^{100}$ INTA. INTA_Public consultation TPD_comments re Plain Packaging. Op. Cit.

${ }^{101}$ Ibid.

${ }^{102}$ A ASIPI é uma organização sem fins lucrativos cujo objetivo principal é promover o desenvolvimento e harmonização das leis, regulamentos e procedimentos relativos à propriedade industrial e intelectual nos países da América. Vide <http://www.asipi.org/> para maiores informações. Acesso em 29 de abril de 2014.
} 
modo que a situação não é extrema o suficiente para justificar uma medida tão drástica, não havendo, então, razoabilidade alguma. ${ }^{103}$

Outras entidades fizeram uma declaração conjunta para exteriorizar um entendimento sobre o Plain Packaging. Em tal documento, reuniram seus entendimentos a APRAM (Association of Trademarks and Designs rights Practitioners), ICC (International Chamber of Commerce), BMM (Benelux Trademark Association), ECTA (European Communities Trade Mark Association), MARQUES, UNIFAB (Union des Fabricants) e UNION IP (European Practitioners in Intellectual Property). ${ }^{104}$

Em tal documento, as entidades citadas expõem seu entendimento de no sentido de que não deve ser introduzida esta ou qualquer outra medida de legislação extrema que não permita, ao todo ou em parte, que os titulares de marcas de cigarro de as usarem legitimamente. Destacam, ainda, que a medida atenta contra a proteção legal e que possivelmente aumentará a existência do mercado ilegal ${ }^{105}$.

No Brasil, a ABPI - Associação Brasileira da Propriedade Intelectual $^{106}$ - também emitiu parecer sobre o assunto. A ABPI destacou que entende a importância de medidas efetivas que claramente informem ao consumidor sobre os riscos dos produtos de tabaco. No entanto, defende que o Plain Packaging compromete seriamente o sistema de proteção

\footnotetext{
${ }^{103}$ ASIPI. Public Consultation on Tobacco Plain Packaging Bill 2011. Disponível em

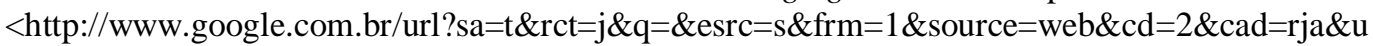
act $=8 \&$ ved $=0 \mathrm{CDQQFjAB} \&$ url $=\mathrm{http} \% 3 \mathrm{~A} \% 2 \mathrm{~F} \% 2 \mathrm{Fwww}$. smoke-free.ca $\% 2 \mathrm{Fplain}-$ packaging\%2Fdocuments\%2F2011\%2FInter\%2520American\%2520Association\%2520of\%2520In tellectual\%2520Property.pdf\&ei=fNNeU92TFumj8AHr-ID4Bw\&usg=AFQjCNHEw0AGr0jVDfgUFW5VP7ouCP_iA\&bvm=bv.65397613,d.cWc > Acesso em 14 de maio de 2014.

104 Para mais informações sobre as referidas entidades, vide <http://apram.com/>, <http://www.iccwbo.org/>, <http://www.bmm.be>, <http://www.ecta.org/>, <http://www.marques.org/>, <http://www.unifab.com/> e <www.union-ip.org/>. Acesso em $29 \mathrm{de}$ abril de 2014.

${ }^{105}$ MARQUES. Joint Statement - Reflection onto the adoption of Plain Packaging legislations, of Sister Associations APRAM, BMM, ICC-BASCAP, ECTA, MARQUES, UNION DES FABRICANTS, UNION-IP. Disponível em <http://www.marques.org/positionpapers/default.asp>. Acesso em 29 de abril de 2014.

106 a ABPI é uma entidade sem fins lucrativos voltada para o estudo da Propriedade Intelectual, notadamente o direito da propriedade industrial, o direito autoral, o direito da concorrência, a transferência de tecnologia e outros ramos afins. <Vide http://www.abpi.org.br/>. Acesso em 01 de maio de 2014.
} 
internacional à Propriedade Intelectual, de forma a violar o TRIPs e a CUP, além de constituir expropriação sem pagamento de indenização. ${ }^{107}$

107 ABPI. ABPI's comments on the Australian Government Consultation Paper on Tobacco Plain Packaging. Disponível em <http://www.smoke-free.ca/plainpackaging/documents/2011/ABPI\%20-\%20Brazil.pdf> . Acesso em 01 de maio de 2014. 


\section{Síntese Conclusiva}

As embalagens genéricas são uma medida restritiva que envolve a colisão de diversos direitos e princípios. Apesar de louvável a intenção de proteger o consumidor e buscar a proteção à saúde, constitucionalmente protegida, existe outras maneiras menos gravosas de intervir no mercado de cigarro.

A introdução do Plain Packaging no Brasil implicaria em diversas violações já mencionadas no presente trabalho. A violação dos direitos de propriedade industrial dos titulares de marcas referentes a produtos derivados de tabaco tem impactos que vão além do mercado de tabaco. Outros setores industriais são afetados, já que, uma vez descumpridos tratados internacionais ratificados pelo Brasil, o regime de propriedade intelectual no país são postos em questionamento, gerando-se uma insegurança jurídica por parte dos titulares de tais direitos.

É possível que empresas estrangeiras deixem de adentrar e investir no mercado brasileiro ao perceber o desrespeito a ativos intelectuais por parte do governo, bem como ao vislumbrar o descumprimento de tratados internacionais.

Desta forma, a introdução do Plain Packaging consiste num ataque desmedido aos direitos de propriedade intelectual, com consequências negativas que não são válidas diante de tão pouca comprovação de efetividade da medida. Existem medidas alternativas que atingiriam melhor o objetivo sem tamanha violação aos direitos dos proprietários, e sem consequências não intencionais tão graves.

É importante ressaltar que as embalagens genéricas são uma restrição de marca que proíbe o titular de um direito de usufruir de seu direito de propriedade intelectual com relação a um produto lícito. Assim, cria-se uma classe de produtos em que a proteção universal aos direitos de propriedade intelectual não são aplicáveis. 
É necessário considerar ainda que, se tal discriminação for adotada, a intervenção regulatória provavelmente se estenderá a outros produtos considerados nocivos ou controversos pela sociedade. O setor de fast foods e bebidas alcoólicas, por exemplo, são dois potenciais ameaçados.

"Como evitar que a emissão de mensagens dotadas aparentemente de uma finalidade legítima não venha a mascarar uma intenção de impor à sociedade uma determinada concepção de mundo lesiva à autonomia individual?"108

${ }^{108}$ DIAS, Eduardo Rocha. Direito à Saúde e Informação Administrativa. O caso das advertências relativas a produtos perigosos. p. 19. 


\section{REFERÊNCIAS BIBLIOGRÁFICAS}

ABPI. ABPI'S COMMENTS ON THE AUSTRALIAN GOVERNMENT CONSULTATION PAPER ON TOBACCO PLAIN PACKAGING. DISPONÍVEL EM

<HTTP://WWW.SMOKE-FREE.CA/PLAIN-

PACKAGING/DOCUMENTS/2011/ABPI\%20-\%20BRAZIL.PDF>.

ACTBR. EMBALAGEM GENÉRICA DE PRODUTOS DE TABACO:

PROTEGENDO CRIANÇAS, ADOLESCENTES E JOVENS DO

MARKETING DA INDÚSTRIA DO TABACO. DISPONÍVEL EM

<WWW.ACTBR.ORG.BR/UPLOADS/CONTEUDO/738_EMBALAGEM_GENERICA.

PDF.>

ACTBR. EMBALAGEM E INFORMAÇÕES PARA OS CONSUMIDORES NOS MAÇOS DE CIGARROS. DISPONÍVEL EM

$<$ HTTP://WWW.GOOGLE.COM.BR/URL?SA=T\&RCT=J\&Q=\&ESRC=S\&FRM=1\& SOURCE $=$ WEB $\& C D=1 \& V E D=0 C D M Q F J A A \& U R L=H T T P \% 3 \mathrm{~A} \% 2 F \% 2 F A C T B$ R.ORG.BR\%2FUPLOADS\%2FCONTEUDO\%2F106_EMBALAGEM-EINFORMACOES-CONSUMIDORES-MACOS-DE-

CIGARROS.PDF\&EI=QGDHU8IPN66I0GHXTYDYAQ\&USG=AFQJCNE7H0 EG1HGZQ6VKAJVKBHI7EKEZ7Q>.

ACTBR. RELATÓRIO DA PESQUISA ITC BRASIL SOBRE

Publicidade, PRomoÇÃo e PATRocínio de TABACO . DisPoníVEL EM <ACTBR.ORG.BR/UPLOADS/CONTEUDO/810_ITC_BRAZIL.PDF>.

ARAGÃO, AleXandre Santos DE. CURSo DE DiREito AdMinistrativo. ED. ForENSE. 2A EDIÇÃO. RiO DE JANEIRO: EDITORA ForENSE, 2013. P. 267 -273 . 
ARAÚJO JR., JOSÉ TAVARES DE. REGULAÇÃO DA INDÚSTRIA DE CIGARROS NO BRASIL IN REVISTA IBRAC, VOL. 16, ‥․ 2, P. 6.

ASIPI. Public CONSULTATION on TobaCCo Plain PACKAGING BILL 2011. DISPONÍVEL EM

<HTTP://WWW.GOOGLE.COM.BR/URL?SA=T\&RCT=J\&Q=\&ESRC=S\&FRM $=1 \&$ SOURCE $=$ WEB $\& C D=2 \& C A D=R J A \& U A C T=8 \& \mathrm{VED}=0 \mathrm{CDQQFJAB} \& U \mathrm{URL}=\mathrm{HTT}$ P\%3A\%2F\%2FWWW.SMOKE-FREE.CA\%2FPLAINPACKAGING\%2FDOCUMENTS\%2F2011\%2FINTER\%2520AMERICAN\%2520 ASSOCIATION\%2520OF\%2520INTELLECTUAL \% 2520PROPERTY.PDF\&EI=FN NEU92TFUMJ8AHR-ID4Bw\&USG=AFQJCNHEw0AGR0JVDFGUFW5VP7OUCP_IA\&BVM=BV.65397613,D.CWC >

AUSTRALIAN GOVERNMENT. TOBACCO PLAIN PACKAGING ACT 2011. DISPONÍVEL EM <HTTP://WWW.COMLAW.GOV.AU/DETAILS/C2011A00148/DOWNLOAD>. ACESSO EM 11/04/2014.

AUSTRALIAN GOVERNMENT. TRADE MARKS ACT 1995. DISPONÍVEL EM <HTTP://WWW.COMLAW.GOV.AU/DETAILS/C2013C00143>.

BINENBOJM, GUSTAVO. ASFIXIA REGULATÓRIA. DISPONÍVEL EM $<$ HTTP://OGLOBO.GLOBO.COM/IN/ASFIXIA-REGULATORIA2902104\#IXZZ30TRIV8SF>.

BONADIO, ENRICO. PLAIN PACKAGING OF TOBACCO PRODUCTS UNDER EU INTELLECTUAL PROPERTY LAW. DISPONÍVEL EM < FILE:///C:/DOCUMENTS\%20AND\%20SETTINGS/GELSON/MEUS\%20DOCUME NTOS/DOWNLOADS/SSRN-ID2174453.PDF > 
BRITISH AMERICAN TOBACCO - UK. UK STANDARISED PACKAGING CONSULTATION. RESPONSE OF BRISH AMERICAN TOBACCO UK LIMITED (08 AUGUST 2012). DiSPONÍVEL EM

<HTTP://WWW.BAT.COM/GROUP/SITES/UK_9D9KCY.NSF/VWPAGESWEBLIV E/DO8WZC5E/\$FILE/MEDMD8WZC6J.PDF >.

CARVALHO FILHO, José dos SANTOS. MANUAL DE DIREITO AdMinistrativo. 23 a EDIÇÃO. RiO DE JANEIRO: LUMEN JURIS, 2010. P. 44

DAVIDSON, MARK. Plain PACKAGING of ToBACCO AND THE "RIGHT" TO USE A TRADE MARK. EM EUROPEAN INTELLECTUAL PROPERTY REVIEW, 2012. DISPONÍVEL EM < HTTP://PAPERS.SSRN.COM/SOL3/PAPERS.CFM?ABSTRACT_ID=2137455>.

DECRETO No 5.658, DE 2 DE JANEIRO DE 2006. DISPONÍVEL EM <HTTP://WWW.PLANALTO.GOV.BR/CCIVIL_03/_ATO20042006/2006/DECRETO/D5658.HTM>.

DEPARTMENT OF HEALTH. CONSULTATION ON THE FUTURE OF TOBACCO CONTROL. DISPONÍVEL EM <HTTP://WEBARCHIVE.NATIONALARCHIVES.GOV.UK/20130107105354/HTTP ://WWW.DH.GOV.UK/PROD_CONSUM_DH/GROUPS/DH_DIGITALASSETS/DOCU MENTS/DIGITALASSET/DH_085651.PDF>.

DEPARTMENT OF HEALTH. IRELAND SET TO BECOME SECOND COUNTRY IN THE WORLD TO INTRODUCE PLAIN PACK CIGARETTES. DISPONÍVEL EM <HTTP://WWW.DOHC.IE/PRESS/RELEASES/2013/20130528.HTML>.

DIAS, EDUARDO ROCHA. DIREITO À SAÚDE E INFORMAÇÃO ADMINISTRATIVA. O CASO DAS ADVERTÊNCIAS RELATIVAS A PRODUTOS PERIGOSOS. 1ª EDIÇÃO. BELO HORIZONTE: EDITORA FÓRUM, 2008. P. 270. 
ECONOMIESUISSE. INTELLECTUAL PROPERTY VIOLATIONS RESULTING FROM EXCESSIVE PACKAGING RESTRICTIONS. DISPONÍVEL EM <HTTP://WWW.GOOGLE.COM.BR/URL?SA=T\&RCT $=\mathrm{J} \& \mathrm{Q}=\& E S R C=\mathrm{S} \& \mathrm{FRM}=1 \&$ SOURCE $=$ WEB $\& C D=1 \& C A D=R J A \& U A C T=8 \& V E D=0 C C 8 Q F J A A \& U R L=H T T P$ \%3A\%2F\%2FWWW.SMOKE-FREE.CA\%2FTRADE-ANDTOBACCO\%2FRESOURCES\%2FINDUSTRYFRIENDLY\%2FECONOMIESUISSE_P OSITION_PAPER_ON_GENERIC_LABELLING_NOVEMBER_2009.PDF\&EI=TPZU9HFHRG-SQSZMOHYCG\&USG=AFQJCNH3N8KJEJUGCLCIJSTUVCGHWKMSG\&BVM=BV.66917471,D.CWC>.

EUROPA.EU. PERGUNTAS E RESPOSTAS: NOVAS REGRAS PARA OS PRODUTOS DO TABACO. DISPONÍVEL EM <HTTP://EUROPA.EU/RAPID/PRESSRELEASE_MEMO-14-134_PT.HTM>.

INTA. AUSTRALIA TOBACCO Plain PACKAGING BILL 2011 COMMENTS. DISPONÍVEL EM <HTTP:/WWW.INTA.ORG/ADVOCACY/DOCUMENTS/JUNE32011.PDF>.

HARVEY, BENJAMIN. TURKEY WORKING ON CIGARETTE BRANDING BAN LAW, MiLLIYET SAYS. DisPONÍVEL EM <HTTP://WWW.BLOOMBERG.COM/NEWS/2011-09-07/TURKEY-WORKING-ONCIGARETTE-BRANDING-BAN-LAW-MILLIYET-SAYS.HTML>

HIGH COURT OF AUSTRALIA. BRITISH AMERICAN TOBACCO AUSTRALASIA LIMITED AND ORS V. THE COMMONWEALTH OF AUSTRALIA. DiSPONÍVEL EM <HTTP://WWW.HCOURT.GOV.AU/CASES/CASE-S389/2011>.

HIGH COURT OF AUSTRALIA. JT INTERNATIONAL SA V COMMONWEALTH OF AUSTRALIA [2012] HCA 43 (5 OCTOBER 2012). VIDE <HTTP://WWW.AUSTLII.EDU.AU/AU/CASES/CTH/HCA/2012/43.HTML〉. 
INCA. OBSERVATÓRIO DA POLÍTICA NACIONAL DE CONTROLE DO TABACO.

<HTTP://WWW2.INCA.GOV.BR/WPS/WCM/CONNECT/OBSERVATORIO_CONTRO LE_TABACO/SITE/HOME/CONVENCAO_QUADRO/O_QUE_E>. ACESSO EM 04 DE MAIO DE 2014.

INCA. CONVENÇÃO-QUADRO PARA O CONTROLE DO TABACO. DiSPONÍVEL EM

<HTTP://WWW2.INCA.GOV.BR/WPS/WCM/CONNECT/5A3ABD004EB68A22A09 BB2F11FAE00EE/CONVEN\%C3\%A7\%C3\%A3OQUADRO+PARA+O+CONTROLE+DO+TABACO+EM+PORTUGU\%C3\%AAS.PD F?MOD=AJPERES\&CACHEID=5A3ABD004EB68A22A09BB2F11FAE00EE $>$.

INTA. INTA_PUBLIC CONSULTATION TPD_COMMENTS RE PLAIN PACKAGING . DISPONÍVEL EM <HTTP://WWW.INTA.ORG/PDF\%20LIBRARY/INTA_PUBLIC\%20CONSULTATI ON\%20TPD_COMMENTS\%20RE\%20PLAIN\%20PACKAGING.PDF>

INPI. CONVENÇÃO DE PARIS. DISPONÍVEL EM <HTTP://WWW.INPI.GOV.BR/IMAGES/STORIES/CUP.PDF〉.

HEURTAUT, DIANE. TABAC: LA LIGUE CONTRE LE CANCER VEUT DES PAQUETS DE CIGARETTES "NEUTRES". DiSPONÍVEL EM <HTTP://LCI.TF1.FR/SCIENCE/TABAC-LA-LIGUE-CONTRE-LE-CANCER-VEUTDES-PAQUETS-DE-CIGARETTES-6968916.HTML>

MARQUES. JOINT STATEMENT - REFLECTION ONTO THE ADOPTION OF PLAIN PACKAGING LEGISLATIONS, OF SISTER ASSOCIATIONS APRAM, BMM, ICCBASCAP, ECTA, MARQUES, UNION DES FABRICANTS, UNION-IP. 
DISPONÍVEL EM

<HTTP://WWW.MARQUES.ORG/POSITIONPAPERS/DEFAULT.ASP>. ACESSO EM.

MINISTRY OF HEALTH. PROPOSAL TO INTRODUCE PLAIN PACKAGING OF TOBACCO PRODUCTS IN NEW ZEALAND. DISPONÍVEL EM

<HTTP://WWW.SMOKE-FREE.CA/TRADE-AND-

TOBACCO/NEW\%20ZEALAND/PROPOSAL-TO-INTRODUCE-PLAIN-

PACKAGING-TOBACCO-PRODUCTS-IN-NZ-CONSULTATION.PDF>

PARLIAMENT OF AUSTRALIA. COMMONWEALTH OF AUSTRALIA

CONSTITUTION ACT. DiSPONÍVEL EM

<HTTP://WWW.APH.GOV.AU/ABOUT_PARLIAMENT/SENATE/POWERS_PRACTI CE_N_PROCEDURES/ /LINK.ASPX?_ID=F74707A5A4934E05A67EE5969B1 $56435 \& \_Z=Z>$.

PHILIP MORRIS. EXECUTIVE SUMMARY OF SUBMISSION BY PHILIP MORRIS (NEW ZEALAND) LIMITED TO THE MINISTRY OF HEALTH CONSULTATION ON Plain Packaging of TobacCo PRoducts. Plain PACKAGing of tobaCCo PRODUCTS WILL NOT REDUCE SMOKING RATES, AND WILL VIOLATE NEW ZEALAND'S INTERNATIONAL TRADE OBLIGATIONS. NEW ZEALAND, 2012. DISPONÍVEL EM <HTTP://WWW.PMI.COM/ENG/TOBACCO_REGULATION/SUBMISSIONS/DOCUM ENTS/EXECUTIVE_SUMMARY_OF_PMNZ_SUBMISSION_ON_PLAIN_PACKAG ING_FINAL.PDF.>.

PROJETO DE LEI SMOKE-FREE ENVIRONMENTS (TOBACCO PLAIN PACKAGING) AMENDMENT BILL. DISPONÍVEL EM <HTTP://WWW.LEGISLATION.GOVT.NZ/BILL/GOVERNMENT/2013/0186/LATES T/WHOLE.HTML\#DLM5821008> 
RIMMER, MATHEW. CIGARETTES WILL KILL YOU: THE HIGH COURT OF AUSTRALIA \& PLAIN PACKAGING OF TOBACCO PRODUCTS. DISPONÍVEL EM <HTTP://WWW.WIPO.INT/WIPO_MAGAZINE/EN/2013/01/ARTICLE_0005.HTML $>$.

SENADO FEDERAL. PLS 103 DE 2014. DISPONÍVEL EM <HTTP://WWW.SENADO.GOV.BR/ATIVIDADE/MATERIA/DETALHES.ASP?P_CO D_MATE=116679>. ACESSO EM 27 DE MARÇO DE 2014.

SENADO FEDERAL. PLS 154/2012 E 103/2014. DISPONÍVEIS EM <HTTP://WWW.SENADO.GOV.BR/ATIVIDADE/MATERIA/CONSULTA_PARL.ASP ?RAD_TIP=PLS\&TIPO_CONS=15\&FLAGTOT=1\&P_COD_SENADOR=4593 \&P_COD_COMISSAO $=>$. SOUZA CRUZ. O MERCADO DE CIGARROS. DISPONÍVEL EM <HTTP://WWW.SOUZACRUZ.COM.BR/GROUP/SITES/SOU_7UVF24.NSF/VWPAG ESWEBLIVE/DO7V9KNX?OPENDOCUMENT\&SKN=2>.

THE CONNEXION. Plain CIGARETTE PACKETS CONSIDERED. DiSPONÍVEL EM <HTTP://WWW.CONNEXIONFRANCE.COM/PLAIN-CIGARETTE-PACKETSSMOKING-DRAFT-LAW-LOGOS-COLOURS-BANNED-SHOCK-IMAGES-VIEWARTICLE.HTML>

WORLD TRADE ORGANIZATION. TRIPS: AGREEMENT ON TRADERELATED ASPECTS OF INTELLECTUAL PROPERTY RIGHTS.

DISPONÍVEL EM <HTTP://WWW.WTO.ORG/ENGLISH/TRATOP_E/TRIPS_E/T_AGM1_E.HTM>. 